\title{
ABERRANT DNA METHYLATIONOF RUN DOMAIN CONTAINING 3B IN LYMPHOID MALIGNANCIES
}

A Thesis
presented to
the Faculty of the Graduate School
at the University of Missouri-Columbia
In Partial Fulfillment
of the Requirements for the Degree
Master of Science
Dr. Kristen H Taylor, Thesis Supervisor
JULY 2013
by B B


The undersigned, appointed by the Dean of the Graduate School, have examined the thesis entitled

\title{
ABERRANT DNA METHYLATIONOF RUNDOMAIN CONTAINING 3B IN LYMPHOID MALIGNANCIES
}

\section{Presented by DANE BURMEISTER}

A candidate for the degree of Master of Science

And hereby certify that, in their opinion, it is worthy of acceptance.

\author{
Kristen Taylor, Ph.D.
}

Wade Davis, Ph.D.

Gerald Arthur, M.D. M.S. 


\section{ACKNOWLEDGEMENTS}

First and foremost I would like to acknowledge my academic advisor Dr. Kristen H. Taylor. I am sure it is not easy to select your first graduate student and I am very grateful for the opportunity to be hers. Dr. Taylor's patience and guidance is the reason this project is now completed. I have to give her a great deal of credit for investing so much time and effort in a student with little research experience while always approaching my development with positivity and encouragement. I would also like to thank the other members of my thesis committee: Dr. Wade Davis and Dr. Gerald Arthur. Both of these men were nothing but helpful and accommodating. Their contributions to my project would have been sorely missed had they not agreed to be involved.

I would also like to acknowledge the many people I've worked with in our lab. Thank you to Dr. Stephanie McKay, Jie Ning, and Jennifer Schnabel who all, at one point or another, helped facilitate my transition into a functional scientist. Another big thank you goes out to Dan Miller, Melanie Spoor, and Allison Tegge for their guidance and advice on being a graduate student. Thank you to the undergraduate students who worked in our lab, RiyaSohel, Brad Collins, and Annette Van Swaay for supporting my growth as a mentor. Finally, a great big thank you goes to MdAlmamun. I sat next to Mamun everyday through this entire process and he was always the first person I turned to; not just because of the proximity of our desks.

To conclude the acknowledgements I would like to thank my parents and close family. They are the most supportive people I know and instilled the values in me that allowed me to complete this project. The biggest thank you of all goes to Stephanie Loria; her ambition and work ethic are a constant source of inspiration. 


\section{TABLE OF CONTENTS}

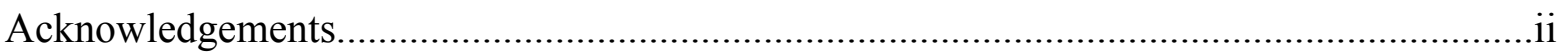

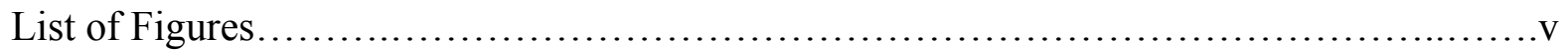

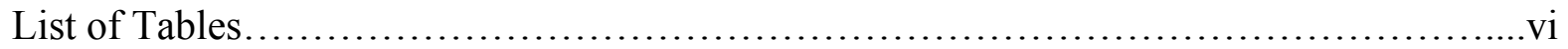

Nomenclature.......................................................................

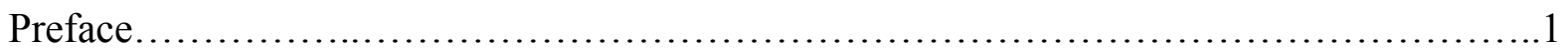

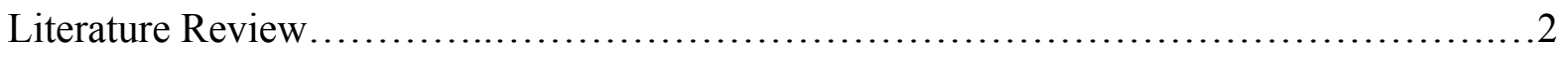

Lymphoid Malignancies..................................................... 2

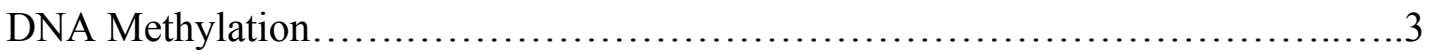

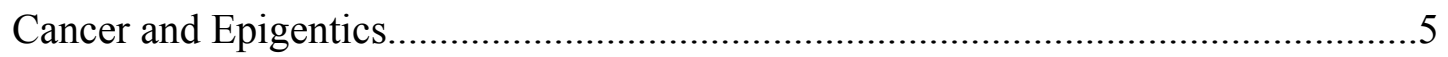

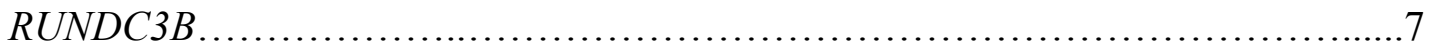

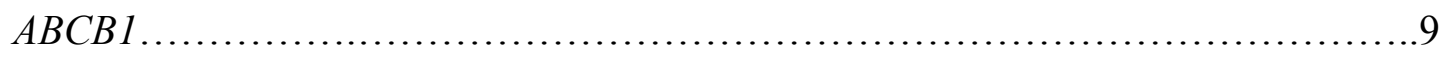

Canonical Wnt Signaling in Cancer and Lymphoid Tissues..........................10

Summary of $R U N D C 3 B$ Research and Rationale for Thesis............................... 10

Experimental Aims and Hypothesis................................................... 12

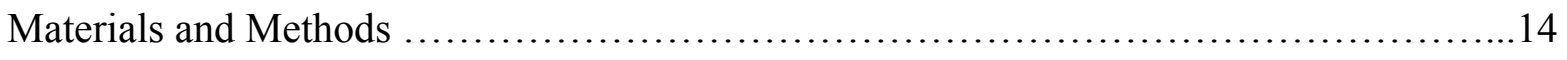

Cell Line Selection......................................................... 14

DNA Quality Check.........................................................

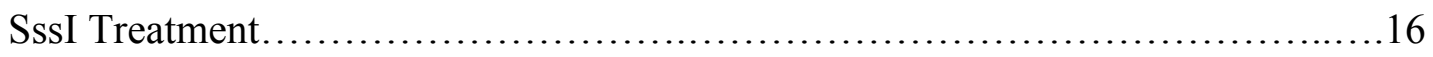

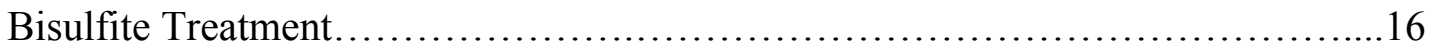

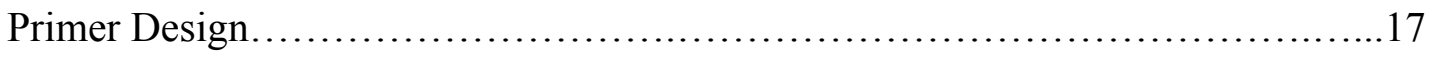

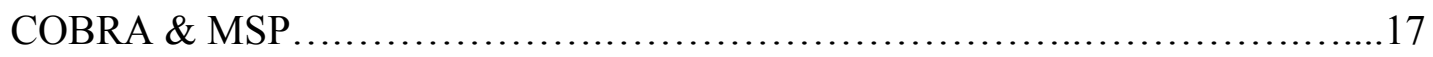

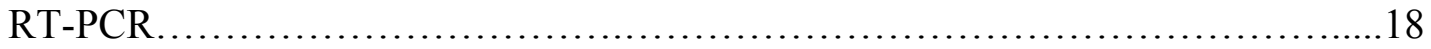




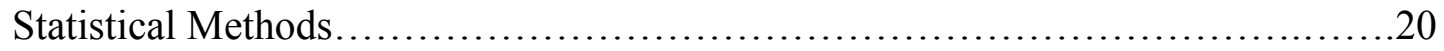

RUNDC3B DNA Sequence Analysis...........................................21

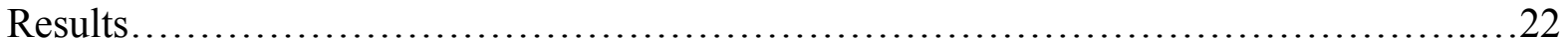

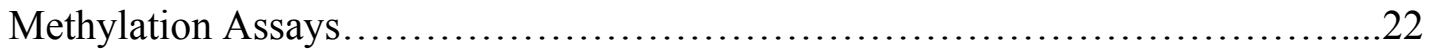

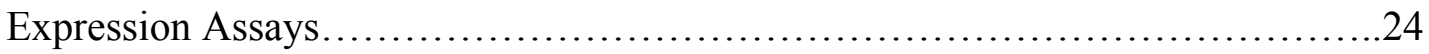

RUNDC3B DNA Sequence Analysis............................................27

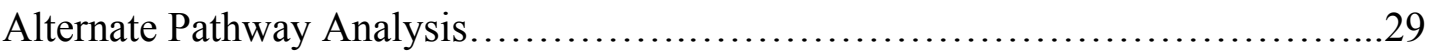

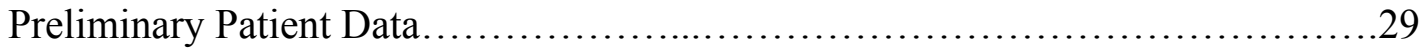

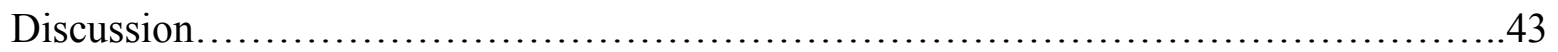

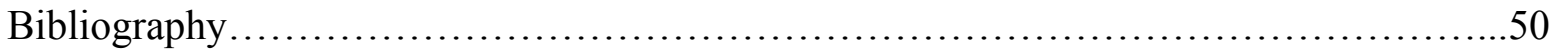

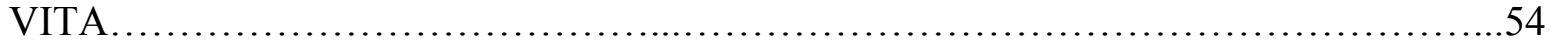

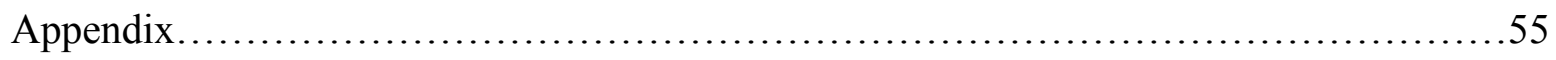




\section{LIST OF FIGURES}

Figure.1 Promoter region of $R U N D C 3 B$ and the location of primers used in methylation....33

Figure.2 Workflow of methylation assays COBRA and MSP...........................34

Figure .3 A representative sample of COBRA results................................. 35

Figure.4 A representative sample of MSP results................................. 35

Figure.5 Results of methylation assays......................................... 36

Figure.6 Summary of methylation and expression assays.............................38

Figure.7 $R U N D C 3 B$ CGI methylation and the effect on neighboring gene expression........39

Figure.8 Regulatory elements of the $R U N D C 3 B$ promoter region and conservation of

putative TFBS across species..............................................41

Figure.9 RUNDC3B promoter methylation in phases of $\mathrm{B}$ cell development................42

Figure.10 Aberrant silencing of $R U N D C 3 B$ may lead to increased expression of Wnt target

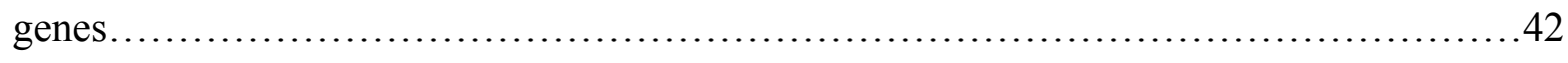




\section{LIST OF TABLES}

Table.1 Summary of cell lines and donor samples .................................. 31

Table.2 SssI treatment reaction components and concentrations.......................32

Table.3 $R U N D C 3 B$ CGI primer information........................................ 34

Table.4COBRA, MSP, and Bst-U1 enzyme digestreaction components and

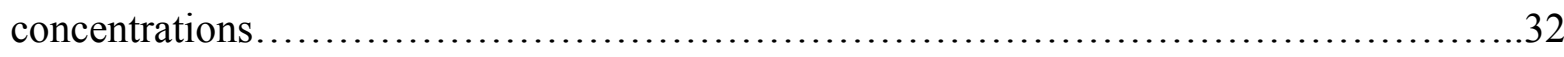

Table.5RT-PCR reaction components and concentrations.............................. 32

Table.6Odds Ratio Illustration................................................

Table.7 Methylation across the $R U N D C 3 B$ CGI is associated with expression of

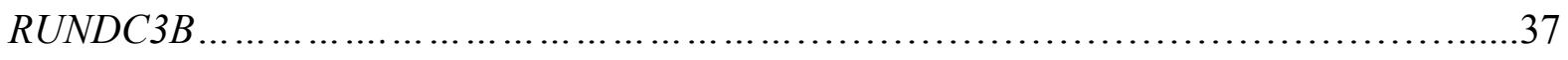

Table.8 Odds Ratio resultsfor associations between $R U N D C 3 B$ CGI methylation and

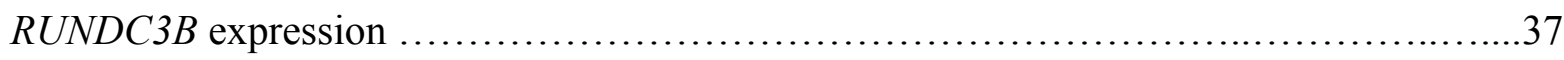

Table.9 Spearman's correlation results for associations between RUNDC3BCGImethylation

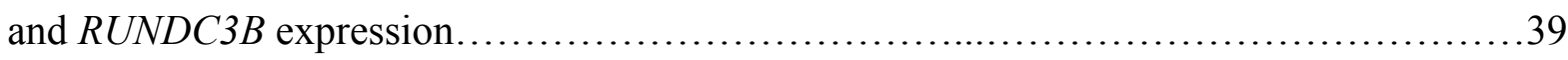

Table.10Comparison of location of putative EGR-3 TFBS across species................41 
NOMENCLATURE

5-AZA

ABCB1

ALL

AP-2

BL

BLAST

CD

CGI

CLL

COBRA

$\mathrm{CpG}$

CSNK1G1/2

$\mathrm{Ct}$

CT conversion reagent

DLBCL

DMR

DNA

DNMT1

EGR-3

FL

G9a 5'-azacytosine

ATP-binding cassette sub-family B member 1

Acute Lymphoblastic Leukemia

Activating Protein-2

Burkitt's Lymphoma

Basic Local Alignment Search Tool

Cluster of Differentiation

CpG Island

Chronic Lymphoblastic Leukemia

Combined Bisulfite Restriction Analysis

Cytosine-phospho-group-Guanine

Casein Kinase 1 Gamma 1/2

Cycle Threshold

Cytosine-Thymine conversion reagent

Diffuse Large B cell Lymphoma

Differentially Methylated Region

Deoxyribonucleic acid

DNA methyltransferase 1

Early Growth Response-3

Follicular Lymphoma

A histone methyltransferase 


$\begin{array}{ll}\text { GAPDH } & \text { Glyceraldehyde 3-phosphate dehydrogenase } \\ \text { HSC } & \text { Hematopoietic Stem Cells } \\ \text { MAPK } & \text { Mitogen Activated Protein Kinase } \\ \text { MBD } & \text { Methyl Binding Domain } \\ \text { MCL } & \text { Mantle Cell Lymphoma } \\ \text { MRD } & \text { Minimal Residual Disease } \\ \text { MSP } & \text { Methylation Specific Polymerase Chain Reaction } \\ \text { NCBI } & \text { National Center for Biotechnology Information } \\ \text { NHL } & \text { Non-Hodgkin's Lymphoma } \\ \text { PCR } & \text { Polymerase Chain Reaction } \\ \text { RNA } & \text { Ribonucleic Acid } \\ \text { RT-PCR } & \text { Real Time Polymerase Chain Reaction } \\ \text { RUNDC3A } & \text { RUN domain containing protein 3A } \\ \text { RUNDC3B } & \text { RUN domain containing protein 3B } \\ \text { siRNA } & \text { Small Interfering Ribonucleic Acid } \\ \text { TFBS } & \text { Transcription Factor Binding Site } \\ \text { UCSC Genome Brower } & \text { University of California Santa Cruz Genome Browser } \\ \text { UTR } & \text { Untranscribed Region }\end{array}$




\section{PREFACE}

The goal of this research proposal is to investigate the epigenetic modification known as DNA methylation and how it can contribute to the development of lymphoid malignancies. Specifically, how the aberrant methylation of the $R U N D C 3 B$ gene can, in part, induce tumorigenesis. By analyzing the methylation status of the promoter region of $R U N D C 3 B$ in lymphomas, leukemia, myelomas, solid tumors and unaffected samples the prevalence of aberrant methylation was determined. Epigenetic regulation wasestablishedbyanalyzing the methylation data in conjunction with $R U N D C 3 B$ expression data. Finally, by determining possible links between $R U N D C 3 B$ silencing and the physiology of cancer a novel hypothesis for the role of RUNDC3B in lymphoma and leukemia pathogenesis was formulated.

Our experiments revealed that aberrant DNA methylation of the RUNDC3BCGI is more prevalent in lymphoid malignancies. The samples displaying this epigenetic misregulationalso exhibited downregulation of the gene.Further analysis of this differentially methylated region (DMR) revealed that it contains evolutionarily conserved regulatory elements, providing evidence that this region may have an important regulatory function in the vertebrate genome. The experimental findings suggest that $R U N D C 3 B$ should be studied further as an understanding of its physiological role could yield important pathogenic insights. 


\section{LITERATURE REVIEW}

\section{Lymphoid Malignancies}

At times the number of distinct cancers that can occur in lymphoid tissues is daunting. Malignancies can develop during every phase of B cell development and this can occur across a wide range of ages. The variations of the morphological and clinical symptoms are high, yet research is elucidating the nature of these cancers. The National Cancer Institute reports the incidence rate of lymphoma is 22.5 per 100,000 men and women per year. It is estimated for 2013 in the U.S. that 69,794 new cases of non-Hodgkin's lymphoma (NHL) will be diagnosed and will cause 19,020 deaths. The five year relative survival rate can range from $61 \%-82 \%$ based on the time of diagnosis. While the median age of diagnosis is 66 specific types of cancer can affect children, such as ALL. The lymphoma of B cells accounts for 16.6 of the reported 22.5 incidences per 100,000 men and women per year. Advances in understanding lymphoma diagnosis and prognosis are crucial to improving treatment for those afflicted by the many types of lymphoid malignancies.

B cell development is a truly amazing process; however the process itself is inherently disposed to cancer formation. At several points during B cell maturation double strand DNA breaks occur. While these processes are critical to forming the distinct antibodies our immune system utilizes to fight infection, it naturally lends itself to chromosomal translocation when the DNA is reassembled. These translocations are capable of activating proto-oncogenes or disrupting tumor suppressor gene expression; changes that could result in the development of cancer. Although these changes are well documented they cannot account for the variation of phenotypes we observe in cancer patients. Thus 
researchers are trying to understand how disease develops without physical alterations of DNA.

\section{DNA Methylation}

In the beginning of the $20^{\text {th }}$ century scientists discovered a "fifth base" contained within our DNA. Bacterial research revealed the presence of modified pyrimidine residues. Specifically, cytosine residues had a methyl group located on the $5^{\text {th }}$ carbon of the ring structure(Johnson and Coghill 1925). In time the modified cytosines were also found in mammalian genomes (Sneiderand Potter1969). In mammals, the methylated cytosine residues occur primarily at $\mathrm{CpG}$ dinucleotide sites.

This research became the starting point of epigenetics. Deriving from the Greek prefix, epigenetics essentially means "over-genetics". Simply put, epigenetics refers to the study of the regulatory modifications of DNA thatphysicallyimpact the behavior of the genome. These modifications are heritable and alter the function of DNA without any changeto the sequence itself. Epigenetic modifications can alter chromatin structure, physically block the access of transcription machinery, and loosen or tighten the attachment of DNA to the structural proteins called histones. As epigenetic research has progressed, the knowledge of how DNA methylation impacts gene activity has greatly increased.

DNA methylation is physically placed on the cytosine residues by enzymes known as DNA methyltransferases. The enzymes operate in one of two ways, either adding methyl residues de novo or maintaining methylation patterns after the replication of DNA during cellular mitosis. The maintenance methyltransferases are critical as they ultimately make DNA methylation heritable. The maintenance enzyme DNMT1 creates a complex with PCNA and G9a in order to access and add methyl groups to the replicating DNA (Esteveet 
al2006). The coding strands retain the methylation mark, but the complementary strands are methylated by DNMT1 to maintain the pattern.The complex recognizes these hemimethylated CpG palindromes and DNMT1 is then able to methylate the unmethyltedCpGsiteson the newly synthesized strand. This is a crucial process as it allows DNA methylation to be inherited through cellular divisions.

DNA methylation can have a powerful effect on gene expression. It has become widely understood that methylated sequences of DNA are transcriptionally repressed (Holliday and Pugh 1975). There are several proteins that are able to identify and bind to methylated $\mathrm{CpG}$ sites and they have become known as Methyl-CpG binding domain proteins (MBD). The mechanisms by which these proteins act to repress DNA transcription are still being studied. It has been demonstrated that some MBDs can recruit histone deacetylases, which can alter chromatin state to a repressed conformation (Jones et al1998). MBDs canalsointeract with large macromolecule complexes such as NuRD that remodel the chromatin structure (Denslowand Wade 2007).

DNA methylation is critical to gene repression throughout the genome. Notably repression due to DNA methylation has a critical role in development. Not only embryonic development, but also in the development of specific tissues. Differentially methylated regions of the genome correspond highly with developmental genes. Often differential patterns of methylation lead to tissue specific gene expression. Furthermore,global DNA methylation within the genome is critical to genomic integrity and studies have illustrated that large-scale demethylation has adverse effects on development (Prokhortchouk and Defossez2008). 
Complex gene regulation mechanisms such as $\mathrm{X}$ inactivation and genomic imprinting involve silencing of one allele (Bird 2002). DNA methylation maintains these important expression patterns. Genes that are active in the germ line, most of which are X-linked, appear to use methylation for complete silencing in somatic cells (De Smetet al 1996, 1999). Another well documented function of DNA methylation is to silence transposable elements. Transposable element-related sequences are heavily methylated and transcriptionally silent in somatic cells (Bird 2002). What is clear from these varied instances of DNA methylation is that it has powerful implications on gene expression and is critical to proper genomic regulation.

CpGdinucleotides are not randomly distributed throughout the genome, but often occur in clumps called CpG islands (CGI). CGIs are typically greater than 500 base pairs in length and have a $\mathrm{C} / \mathrm{G}$ concentration greater than $50 \%$. These qualifications, however, are not rigidly defined. CGIs have been found to occur within the promoter region of genes. Most often these CGIs are unmethylated indicating active transcription. Therefore, if aberrant DNA methylation were to occur in the promoter region of a gene, the gene itself may be repressed.Currently, researchers are attempting to identify hypermethylated CGIs and how they contribute to disease formation.

\section{Cancer and Epigenetics}

Many genetic abnormalities such as mutations and chromosomal translocations have been shown to contribute to cancer formation. Often these genetic changes have been directly linked to classic cancer symptoms which lead to tumor formation, growth, and metastasis. Individual genes have become classified based on how they can contribute to cancer formation when they are aberrantly expressed, regulated, etc. Proto-oncogenes are genes that 
can give a cell a proliferative advantage by promotingthecell cycle, angiogenesis, and/or preventing apoptosis. Tumor suppressor genes work opposite of proto-oncogenes to maintain the delicate balance that is needed to maintain the variety of tissues contained in the human body.

These well documented genetic aberrations are not present in all cancer types nor observed in all patients. Many researchers have now turned to understanding the epigenetic alterations that occur in cancer. The main reason for this is because epigenetic aberrations can also contribute to cancer phenotypes without altering the sequence of DNA.The disruption of normal methylation patterns, with both hypomethylation and hypermethylation events occurring, is a hallmark of tumorigenesis (Baylin and Herman 2000; Robertson and Wolffe 2000). Hypomethylation of proto-oncogenes has been noted in several types of cancer such as liver, lung, colorectal, and some chronic leukemia (Wilsonet al 2007). Hypomethylation of several classic proto-oncogenes such as, C-MYC, H-RAS, K-RAS, and BCL-2 have been well documented in liver cancer (Lin et al2001). In terms of genome-wide changes, hypomethylation has been observed in chronic lymphoblastic leukemia (CLL) and colorectal cancer (Lykoet al 2004). It follows that hypomethylation may lead to the expression of genes that are selectively silenced; genes that can contribute to tumorigenesis.

Typically CGIs make up a small amount of genomic methylation thus hypermethylation in these areas may have negative biological ramifications. To date, aberrant $\mathrm{CpG}$ island methylation has been shown to be associated with the silencing of a number of classic tumor suppressor genes (Rountree 2001). The retinoblastoma gene $(R B)$ is one such gene, it was found to have aberrant methylation in a promoter region CGI in retinoblastomas, gliomas, bladder cancers, and in both small cell and non-small cell lung 
cancers (Sulewskaet al 2007 and Josephet al 2004). Many other tumor suppressor genes have been shown to be aberrantly methylated in various cancer types (Sulewskaet al2007).This illustrates the importance of understanding CGI hypermethylation and its role in cancer formation.

Additionally, aberrant methylation has been shown to be an important biomarker that can be used to identify cancer types. Methylation can also serve as a biomarker to leukemia post treatment. Leukemia relapse is difficult to assess because of minimal residual disease. Relapse is such a big issue because even a single cancer cell can lead to reformation of the disease. Since minimal residual disease can be detected from a very small amount of cells molecular biomarkers are ideal to assess treatment efficacy.

\section{RUNDC3B}

Located on the seventh chromosome, $R U N D C 3 B$ shares high homology with $R U N D C 3 A$, a Rap2 interacting protein. The gene contains a RUN domain in its amino terminus which is associated with Rap protein binding. The RUN domain of the RUNDC proteins is distinctly charged in such a way that Rap proteins can interact. One study suggests the residues Arg-182 and Arg-186 on the helix- $\alpha 5$ provide this specific charge (KukimotoNiinoet al 2006). The RUN domain itself has a different function in other proteins. RUNDC3B is hypothesized to also be a Rap interacting protein; the Rap protein family is a subgroup of the Ras superfamily. The members of this broad group of proteins are all small GTPases. These enzymes work as molecular switches to regulate many cellular functions such as proliferation, differentiation, cell motility, cell polarity, and vesicle trafficking (Wang et al 2003).The misregulation of these cellular functions are commonly associated with cancer formation. The Rap2 protein works as a slow molecular switch and could play a role 
in Ras inhibition (Wang et al 2003). If RUNDC3Bdoes in fact interact with the Rap proteins, themisregulation of $R U N D C 3 B$ expression could adversely affect the GTPase dependent pathways.

$R U N D C 3 B$ has been found to be expressed in many different tissues. The highest amounts occur in brain, thymus, ovary, testis, leukocytes, liver, small intestines, and prostate tissues (Wanget al 2003). The presence of $R U N D C 3 B$ in leukocytes provides a connection to lymphoid malignancies commonly known as either lymphomas or leukemia. If the gene is being aberrantly modified and silenced perhaps it can be demonstrated as a component of leukemogenesis.

An intriguing feature of $R U N D C 3 B C G I$ is the presence of an area of DNase I hypersensitivity. The data from the ENCODE project is available online via the University of Santa Cruz genome browser (UCSC). Other researchers also verified this finding. This is important as DNase I hypersensitivity is an indicator of loose nucleosome arrangement and thus access to gene transcription. This would seem to indicate $R U N D C 3 B$ can be actively transcribed in tissues with this DNA arrangement. According to this information several tissue typesmay be able to express $R U N D C 3 B$ including lymphoid tissues.

Methylation of $R U N D C 3 B$ (formerly known as $R P I B 9$ ) has been reported in leukemia and is associated with a reduction in gene expression (Taylor et al 2007 a). Interestingly, treatment of leukemic cell lines with a demethylating agent restored expression of the $R U N D C 3 B$ gene suggesting that methylation within the promoter of this gene plays a role in the regulation of $R U N D C 3 B$ expression.A study on breast cancer revealed $R U N D C 3 B$ expression to be altered in the tissue, but in this case it was overexpressed. The research revealed that $R U N D C 3 B$ was activated in the primary tumor of breast cancer patients and that 
$R U N D C 3 B$ activation correlates with metastasis (Raguzet al, 2005). Although this is the opposite of what has been demonstrated in ALL, the aberration of $R U N D C 3 B$ expression could be linked to tumorigenesis in lymphomas.

\section{$A B C B 1$}

As our knowledge of the genome has expanded it is apparent that it is a complex and dynamic system. With this in mind, any research relating to the genome and its regulation has to avoid focusing on a single element of the genome. In the case of $R U N D C 3 B$, we need to be mindful of the gene that runs anti-parallel to it; ATP-binding cassette sub-family B member $1(A B C B 1)$. Formerly known as multiple drug resistance 1 gene $(M D R 1)$ the gene encodes a P-glycoprotein. These proteins have been shown to be able to transport various molecules across cellular membranes, includingmany forms of therapeutic drugs (Fardelet al1996).

Some studies have indicated that methylation of $A B C B 1$ promoter can have effects on cancer. One such study observed that hypermethylation in the $M D R 1$ promoter region contributed to disease progression in prostate cancer (Enokidaet al2004). Similar findings were observed in acute myeloid leukemia (AML) (Toyota et al2001). Based on these findings it is important to understand ifthe epigenetic regulation we observe in $R U N D C 3 B$ is also true in $A B C B 1$.

The $A B C B 1$ gene has two transcription start sites (Noonan et al1990). It has been shown that the gene products of either of the two start sites are functionally the same. Interestingly, the two transcriptional start sites are located on either side of our CGI of interest. Based on this arrangement it would seem DNA methylation in the CGI of interest may determine which start site is utilized. Understanding the impact of epigenetic 
modifications on $A B C B$ lexpression is crucial to understanding the larger implications of aberrant methylation in the CGI of interest in cancer development.

\section{Canonical Wnt Signaling in Cancer and Lymphoid Tissues}

Canonical Wnt signaling is a crucial signaling cascade in early development. As research has progressed it has become apparent this signaling cascade also regulates stem

cells. This function of Wnt signaling may be the critical piece of information to associate the cascade with cancer formation (Reya and Clevers 2005). Similar to healthy tissues, tumors begin with stem cells that act as a common blueprint for all new cells; however cancer stem cells begin the formation of tumors. Understanding the behavior and maintenance of cancer stem cells is important to understanding how to treat cancer patients.

As more information about Wnt signaling in healthy tissues becomes known we can begin to elucidate how it is misregulated in a disease. This is the same for hematopoieticcancers. Hematopoietic stem cells (HSCs) are among the most studied stem cells and thus among the most well understood. In these cells Notch, Hedgehog, and Wnt signaling may regulate the self-renewal of HSCs (Duncan et al2005). It has been shown that many Wnt proteins promote the self-renewal in HSC's and undifferentiated progenitors (Malhotra and Kincade 2009).

\section{Summary of Previous Research and Rationale for Thesis}

To validate and extend the methylation status of $R U N D C 3 B$ and its potential role in pathogenesis of ALL reported by Taylor and colleagues (2007), Emily Hoffman's work revealed that various lymphoid malignancy cell lines had different methylation states of the $R U N D C 3 B$ promoter region and that there was an association between CGI methylation and the loss of expression of $R U N D C 3 B$ (unpublished data).The results were found in 9 cell lines 
of lymphoid malignancies. It was also determined in these samples that the methylation status in some areas of the CGI had an association with $R U N D C 3 B$ expression.

Wang and colleagues also set out to expand on the findings of the methylation status of the $R U N D C 3 B$ promoter region. This study was designed to determine the potential of using $R U N D C 3 B$ CGI methylation as a biomarker to detect MRD in blood cancers. By examining the methylation status in lymphoid and myeloid malignancy cell lines it was found that the lymphoid malignancies, unlike the myeloid malignancy cell lines, showed evidence of methylation in the promoter region of $R U N D C 3 B$ (Wang et al2010). This study did not set out to determine if the expression of $R U N D C 3 B$ was differentially affected by this methylation between tissue types. We hoped to expand on Dr. Wang's findings in this manner.

In addition to the methylation studies, Taylor and colleagues performed a very informative experiment on samples exhibiting methylation. Genes exhibiting differential methylation and subsequent repression in ALL (including RUNDC3B) were treated with the demethylating agent 5-azacytizine (5-AZA) and a histone deactylase inhibitor (TSA). 5-AZA treatment restored the expression of $R U N D C 3 B$ in these samples, while samples treated with TSA exhibited no change in $R U N D C 3 B$ expression. This suggests that $R U N D C 3 B$ is under regulation of DNA methylation and is a crucial finding to developing our hypothesis.

Finally, there is evidence to suggest the Ras signaling pathway may not be the ideal pathway to investigate if we wish to determine how cancer can develop from $R U N D C 3 B$ silencing. Emily Hoffman's work also included PCR plate analysis on genes in the mitogen activated protein kinase (MAPK) pathway. The results suggested that an ALL cell line exhibiting $R U N D C 3 B$ CGI hypermethylation expressed MAPK pathway genes in a similar 
manner as a bone marrow without $R U N D C 3 B$ CGI hypermethylation. Knowing this it would seem that $R U N D C 3 B$ silencing may not have a dramatic effect on Rap2 as its hypothesized function would suggest. Establishing new pathways to investigate is critical to elucidating the role of RUNDC3B in the development of lymphoid malignancies.

What has become apparent is that the $R U N D C 3 B$ gene is altered in lymphoid malignancies and to some extent in breast cancer. To date little information is known about the gene in other cancer types. In this project, we expanded on these findings by including more lymphoid and myeloid blood cancers in our experiments. Additionally, we included several other types of solid tumor cancers and a range of unaffected lymphoid tissues to determine if aberrant methylation is unique to lymphoid cancers.

\section{Experimental Purpose and Experimental Aims}

We hypothesized that DNA methylation in the promoter region of the $R U N D C 3 B$ gene is unique to lymphoid malignancies and that this epigenetic modification contributes to the development of these cancers. To date, the function of RUNDC3B is only hypothesized. The goals of this study were to determine if aberrant methlyation of the $R U N D C 3 B$ CGI is present in lymphoid malignancies and absent in myeloid malignancies and solid tumors and begin to elucidate the function of RUNDC3B and its contribution to the development of cancer. To achieve this purpose experimental aims were designed:

1. Establish the extent of DNA methylation within the CGI that lies in the promoter region of the $R U N D C 3 B$ gene in lymphoid cancer cell lines, myeloid cancer cell lines, solid tumor cell lines and healthy lymphoid tissue.

2. Establish the expression of the RUNDC3B gene in lymphoid cancer cell lines, myeloid cancer cell lines, solid tumor cell lines, and healthy lymphoid tissues. This 
expression data combined with methylation data will be used to establish the epigenetic regulation of the $R U N D C 3 B$ gene.

3. Identify the conservation of the $R U N D C 3 B$ CGI across species. Also identify regulatory elements of the region and determine if they are conserved across species.

4. Identify a signaling pathway that may be affected by $R U N D C 3 B$ silencing in order to provide future avenues of functional research.

The initial focus of these experimental aims was to determine the expression of $R U N D C 3 B$. More specifically, determine the expression of $R U N D C 3 B$ in cell lines with varying degrees of proximal CGI methylation. The expression of $R U N D C 3 B$ will be determined using Taqman 2-step assays. This change in experimental method is to provide greater specificity offered by Taqman primers and probes. By acquiring and analyzing this expression data in conjunction with the methylation data the extent of epigenetic regulation of $R U N D C 3 B$ can be determined. This correlative analysis has yet to be performed on the relationship between $R U N D C 3 B$ CGI hypermethylation and $R U N D C 3 B$ repression. Several statistical methods can be conducted to describe an association between an epigenetics modification and the expression of a gene. The two statistical tests we utilized to analyze our data were odds ratio and Spearman's correlation. While both of these tests analyzed our data differently they both ultimately can verify the connection of $R U N D C 3 B$ silencing and methylation in the proximal CGI.

$A B C B 1$ is in such close proximity to $R U N D C 3 B$ our experiments and analysis must be mindful of the gene. With a gene so relevant to cancer treatment located near $R U N D C 3 B$ any epigenetic modifications we observe may also have an effect on $A B C B 1$ expression. By visualizing the arrangement of these two genes it is clear that any epigenetic modifications to 
the CGI we are studying could affect the expression of either gene (Figure.1). Based on this, a secondary purpose of this study was to demonstrate that any aberrant epigenetic regulation we observed did not affect the expression of $A B C B 1$.

Our experimental aims will also provide further insight into the relationship between $R U N D C 3 B$ CGI hypermethylation and lymphoid malignancies. Our experiments will establish the degree of conservation of the RUNDC3B CGI across species. This can demonstrate the importance of this area as a regulatory region. Additionally, by analyzing the sequence of the RUNDC3B CGI we can elucidate what biological processes are being disrupted by aberrant methylation. Understanding the molecular mechanisms that lead to gene silencing is crucial to developing more sophisticated cancer diagnoses and therapies.

The research of sub cellular contributors to cancer is very important to understanding cancer as a whole. To date a myriad of genetic abnormalities have been identified to contribute to cancer formation and there are still many yet to be characterized. The complexity of a disease such as cancer provides many difficulties to determining diagnosis, prognosis, and treatment. This research was an attempt to increase our knowledge of contributing factors to cancer, specifically cancer of lymphoid tissues.

\section{MATERIALS \& METHODS}

\section{Cell Line Selection}

The cell lines utilized may be grouped into four main categories; lymphoid malignancies, myeloid malignancies, solid tumors, and healthy lymphoid cell lines. We chose these categories in order to expand previous research by determining the state of epigenetic regulation of $R U N D C 3 B$ in various cancer types and healthy tissue. The lymphoid malignancies were also selected to be representative of many types of lymphoid 
malignancies. Call 3, Jurkat, and Nalm 6 are acute lymphoblastic leukemia (ALL) cell lines; Jurkat is ALL of T-cells. Daudi and Raji are both Burkitt's lymphoma cell lines (BL). Mec-1, DB, RL, and Granta are chronic lymphoblastic leukemia (CLL), diffuse large B cell lymphoma (DLBCL), follicular lymphoma (FL) and mantle cell lymphoma (MCL) respectively. The myeloid malignancies include KG-1, KG-1a, and U266B which are two acute myeloid leukemia cell lines and a multiple myeloma respectively. The solid tumor cell lines came from a variety of tissues. Four cell lines are adenocarcinomas WiDr (colon), Hela (cervix), PC3 (prostate), and MB 231 (breast). Two samples are skin cancers, a melanoma and A431, a carcinoma. The final solid tumor cell line selected was A549, a carcinoma of the lung. The final category was healthy cell lines this included three healthy B lymphocytes GM 06990, GM 05392, and GM 00536 and CD 19+ cells extracted from umbilical cord blood. In addition to these cell lines several DNA samples were available from donors. These samples were simply DNA isolated from CD19+ cells from donated peripheral blood. In addition to these, a healthy bone marrow donor was available for our analysis. Since these samples were previously isolated we were unable to obtain RNA from these tissues. A summary of the cell lines is presented in Table.1.

\section{DNA Quality Check}

All DNA samples were previously extracted and stored at $-20^{\circ} \mathrm{C}$. Prior to any experimentation DNA samples were quality checked to ensure the purity and integrity of the DNA. First, the concentration and purity of the samples was determined by using Nanodrop spectrophotometer. The purity of the DNA samples was verified based on the 260/280 ratio. A value of approximately 1.8 and above signified a quality DNA sample. Next, $100 \mathrm{ng}$ of sufficiently pure sample was run on a $1 \%$ agarose gel stained with ethidium bromide (data 
not shown). The DNA integrity was determined by comparing the samples with a $1 \mathrm{~kb}$ standard molecular ladder. Samples showing significant amounts of degradation were not used in any experiments.

\section{SssI Treatment}

In order to confidently determine the methylation status of the various cell lines selected, SssI treated DNA was prepared for the positive control. SssI treated DNA is artificially methylated, such that, every $\mathrm{CpG}$ site has a methyl group added. The treatment is harsh on DNA so our protocol begins with $2.5 \mu \mathrm{g}$ of DNA added to the reaction mixture listed in Table.2. This enzymatic reaction is incubated at $37^{\circ} \mathrm{C}$ for 4 hours. After 2 hours additional SAM $(1 \mu \mathrm{l})$ is added to each reaction. Following SssI treatment the positive control samples are then bisulfite treated.

\section{Bisulfite Treatment}

Bisulfite treatment was performed on all cell line DNA (ZYMO EZ DNA Methylation Gold kit, ZYMO Reasearch, Irvine, CA). This treatment preserves the methylation pattern in DNA. This is an important treatment because DNA methylation is lost during PCR since the reactions lack DNMTs. During the treatment methylated cytosine residues are left unchanged, but any unmethylated cytosine residues will be converted to thymine residues. Later this conversion is used to differentiate methylated DNA from unmethylated DNA.

Bisulfite treatment was completed on DNA isolated from various cancer and healthy cell lines listed in Table.1. Each reaction was completed beginning with $1 \mu \mathrm{g}$ of cell line DNA. CT conversion reagent was added to each sample and incubated at $98^{\circ} \mathrm{C}$ for 10 
minutes and then at $64^{\circ} \mathrm{C}$ for 2.5 hours. Each sample was then isolated and purified in a column. The final elution was completed twice with $25 \mu 1$ of water, for a final total of $50 \mu 1$.

\section{Primer Design}

The online program MethPrimer was utilized to assist in COBRA and MSP primer design. By inputting the DNA sequence of the CGI of interest the program identified optimal primers for the bisulfite converted DNA. Bisulfite converted DNA also amplifies better with smaller regions. By keeping our amplicons fewer than 500 base pairs we hoped to avoid difficulties in PCR. Primer sequences listed in Table.3.

\section{COBRA and MSP}

Following bisulfite treatment the DNA could then be used in PCR. Utilizing the COBRA primers we could amplify each of the regions in all of the cell lines. All PCR amplifications were carried out using Gene Amp system 9700 thermocyclers by Applied Biosystems. PCR reaction recipe is detailed in Table.4A. The PCR programs began with 10 minute denaturation and AmpliTaq Gold hot start at $95^{\circ} \mathrm{C}$. Then 4 touch down cycles of: $95^{\circ}$ $\mathrm{C}$ for 15 seconds, $60-64^{\circ} \mathrm{C}$ for 30 seconds $\left(60^{\circ} \mathrm{C}\right.$ for regions $1,2,3$, and $5 ; 64^{\circ} \mathrm{C}$ for region 4), and $68^{\circ} \mathrm{C}$ for 30 seconds. The annealing temperature is also decreased one degree each cycle. Next 32 cycles of: $95^{\circ} \mathrm{C}$ for 15 seconds, $56-60^{\circ} \mathrm{C}$ for 30 seconds $\left(56^{\circ} \mathrm{C}\right.$ for regions 1 , 2,3 , and $5 ; 60^{\circ} \mathrm{C}$ for region 4 ) and $68^{\circ} \mathrm{C}$ for 30 seconds. Next $68^{\circ} \mathrm{C}$ for 7 minutes, and finally $4^{\circ} \mathrm{C}$ indefinitely. All PCR amplifications were visualized using a $1.5 \%$ agarose gel stained with SYBR Green.

Next, restriction enzyme digest reactions were performed to determine whether the amplified region contained methylated cytosine residues. The Bst-U1 enzyme was used for these reactions. The enzyme cut DNA at CGCG sequences, which were present in each of the 
regions of interest. The enzyme digest reaction recipe is detailed in Table.4B. All enzyme digest reactions were carried out according manufacturer's recommendations (New England Biolabs, Ipswitch, Massachusetts). This called for a 4 hour reaction at $60^{\circ} \mathrm{C}$ using NEB Buffer \#2. All enzyme digests were visualized using a 2.5\% agarose gel stained with SYBR Green. Enzyme cut sites were identified prior to analysis so the expected banding patterns could be identified.

The expected PCR products for the COBRA primers were as follows: region one 300 base pairs; region two 176 base pairs; region four 250 base pairs; region five 240 based pairs. The expected Bst-U1 digest banding patterns for methylated samples were as follows: region one 125, 105, and 68 base pairs; region two 93 and 81 base pairs; region four 143 and 106 base pairs; region five 93, 80, and 63 base pairs.

No acceptable COBRA primers could be generated for region 3; therefore MSP primers were utilized. MSP requires the use of two sets of primers. One set of primers is designed to amplify methylated sequences and one set to amplify unmethylated samples.

PCR amplifications were carried out using Gene Amp system 9700 thermocyclers by Applied Biosystems. The PCR reaction recipe is detailed in Table.4A. The PCR programs began with 10 minute denaturation and AmpliTaq Gold hot start at $95^{\circ} \mathrm{C}$. Then 4 touchdown cycles of: $95^{\circ} \mathrm{C}$ for 15 seconds, $60^{\circ} \mathrm{C}$ for 30 seconds, and $68^{\circ} \mathrm{C}$ for 30 seconds. The annealing temperature is also decreased one degree each cycle. Next 32 cycles of: $95^{\circ} \mathrm{C}$ for 15 seconds, $56^{\circ} \mathrm{C}$ for 30 seconds, and $68^{\circ} \mathrm{C}$ for 30 seconds. Next $68^{\circ} \mathrm{C}$ for 7 minutes, and finally $4^{\circ} \mathrm{C}$ indefinitely. All PCR amplifications were visualized using a 1.5\% agarose gel stained with SYBR Green. The expected PCR product for the methylated sequence primers 
was 373 base pairs. The expected PCR product for the unmethylated sequence primers was 376 base pairs. Summary of methylation assay workflow in Figure. 2 .

\section{RT-PCR}

RNA extracted for experimentation was from both cultured cells (A549, A431, WiDr, GM 06990, DB, MB 231, Cord Blood, and RL) and cell pellets stored in liquid nitrogen (Nalm-6, Jurkat, GM 05392, Raji, Call 3, Mec-1, GM 00536, Daudi,Hela, U226B, Granta, and KG-1). RNA was obtained from cell lines by using the QiagenmiRNeasy Mini Kit. Qiazol reagent lysed these cells and RNA was isolated and purified in a column. Additional treatment with DNase enzyme (Qiagen) was used to remove unwanted DNA from the products. The final elution was completed with $30 \mu \mathrm{l}$ of RNase free water supplied by the kit. RNA samples were obtained for lymphoid malignancies, myeloid malignancies, several types of solid tumors, and healthy lymphoid tissue. Call 3, Nalm 6, Jurkat, Mec 1, DB, Granta, RL, Raji, and Daudi represented the lymphoid malignancies. U226B and KG-1 represented the myeloid malignancies. MB 231, Hela, A 431, A 549, and WiDr represented the solid tumors. GM 06990,GM 00536, GM 05392 and CD 19+ cells isolated from cord blood were the healthy lymphoid tissues analyzed.

RT-PCR reactions were conducted on the Bio Rad iCycleriQ and processed by the software that accompanied the machine. The Taqman reactions were developed based on the protocol for the Taqman EZ RT-PCR kit which suggested using less than 100 ng of RNA per $50 \mu 1$ of reaction (Applied Biosystems, Grand Island, New York). Using the GAPDH control recipe as a template a $20 \mu 1$ recipe was created that is detailed in Table.5. The program began with the reverse transcription which progressed as follows: 2 minutes at $50^{\circ} \mathrm{C}$ to activate uracil-N glycosylase (UNG); 30 minutes at $60^{\circ} \mathrm{C}$ top perform the reverse transcription; 5 
minutes at $95^{\circ} \mathrm{C}$ to deactivate the UNG. Following the reverse transcription, PCR protocol then proceeded as follows: 40 cycles of 20 seconds at $94^{\circ} \mathrm{C}$ then 1 minute at $62^{\circ} \mathrm{C}$. The first temperature served to melt the cDNA template and the second temperature served to anneal and extend. It is during this phase that the iCycler measured the amount of FAM 490 in each reaction. Each sample was run in triplicate and for 3 different genes; $R U N D C 3 B, A B C B 1$ and $G A P D H$ the housekeeping gene.

For each of the cell lines mentioned the cycle threshold $(\mathrm{Ct})$ was established for $R U N D C 3 B, A B C B 1$, and $G A P D H$. Some samples did not express $R U N D C 3 B$ and/or $A B C B 1$ and had a N/A result or a Ct less than 35 (Tables S.1-S.3); these samples were considered non-RUNDC3B/ABCB1 expressing. For each triplicate of $\mathrm{Ct}$ values the average and standard deviation was established. If the standard deviation exceeded .25 the $\mathrm{Ct}$ data would not be consistent enough for our analysis. In these instances the data was reduced to a duplicate by removing the furthest value from the mean. The average was recalculated and this value was used in our analysis. This processing was completed in the RUNDC3B, $A B C B 1$, and $G A P D H$ raw data (Tables S.1-S.3). Following the initial processing of the expression data, the $\Delta \mathrm{Ct}$ for each sample was calculated. This was done by subtracting the $\mathrm{Ct}$ of GAPDH from the $R U N D C 3 B$ or $A B C B 1 \mathrm{Ct}$. This was done to normalize the expression between samples. This would be able to correct for differential expression of $R U N D C 3 B$ and/or $A B C B 1$ based on tissue which is critical in order to compare our samples.

\section{Statistical Methods}

Our data set consisted of 20 samples $(n=20)$. This data set is smaller than our initial methylation data set because we were not able to acquire RNA for some the same samples. The cell lines included nine lymphoid malignancies (Call 3, Nalm 6, Jurkat, Mec-1, DB, 
Granta, RL, Daudi, and Raji), two myeloid malignancies (U226B and KG-1), five solid tumor cell lines (MB 231, Hela, A 431, A 549, and WiDr) and 4 healthy lymphoid cell lines (GM 06990, GM 05392, GM 00536, and CD 19+ cells from cord blood). The methylation status for each sample was recorded in the five regions as unmethylated, partially methylated, or methylated. Additionally, a methylation density score was attributed to each sample to describe the methylation across the CGI. Each region was given a numerical value (1= methylated, $.5=$ partially methylated, and $0=$ unmethylated) and the methylation density was calculated by averaging the numerical values across all regions.

To calculate the odds ratios, the samples were organized into a $2 \times 2$ arrangement based on their methylation and expression status (Table.5). The data was redefined as bivariate data. The methylation data became either methylated (which also included partially methylated) and unmethylated. While the expression data was defined as $R U N D C 3 B$ expressing (Ct below 35) and non-RUNDC3B-expressing (Ct above 35). The odds ratios were then calculated such that they addressed the following question: What are the odds of region X methylation based on the expression of RUNDC3B? The odds ratios including $95 \%$ confidence intervals and p-values were calculated by the MedCalc software.

To ascertain the strength of the associations between the methylation status of a given region and $R U N D C 3 B$ expression Spearman correlations were performed using SPSS software. This analysis ranked $R U N D C 3 B \triangle \mathrm{Ct}$ values then correlated them with the level of methylation. Additional correlations were performed to establish the correlation of methylation density and $R U N D C 3 B$ expression and also between the regions themselves.

\section{DNA Sequence Analysis}


The comparative sequence analysis began by determining which species had annotated CGIs in the promoter region of $R U N D C 3 B$. This information was obtained using UCSC and the National Center of Biotechnology Information(NCBI) databases. The number of $\mathrm{CpG}$ sites within these CGIs was also determined using these databases. After identifying $R U N D C 3 B$ homologs with a CGI within the promoter region of the gene, we then determined the homology of these CGIs between these species and the human sequence. Using basic local alignment search tool (BLAST) the sequence of the human CGI was compared to the annotated CGIs of the other species. Next, the sequence that overlapped with the 5' UTR was removed from each sample and a second set of alignments was completed comparing the human sequence across species.

After we determined the homology across species with annotated CGIs we proceeded to investigate the important elements in the human CGI. Utilizing the information in the USCS genome browser conserved transcription binding factor sites (TBFS) were determined. The TBFS could then be compared to the other species to determine if the sites truly were well conserved. Areas of DNase I hypersensitivity (HS) were also identified in the human.

\section{RESULTS}

\section{Methylation Analysis}

The visualized COBRA results of our positive (SssI) and negative (gDNA) controls allowed us to determine the methylation status of the $R U N D C 3 B$ CGI in the cell lines (Figure.3 Lanes 14 and 16). Samples were categorized as methylated if the digested sample no longer displayed a band the size of the initial PCR product and exhibited the expected enzyme digest banding pattern(Figure.3 Lanes 2, 4, 6, and 8). Occasionally, the absence of

the initial PCR product served as sufficient evidence to qualify the sample as methylated. If 
the PCR product was still present and no enzyme digest banding pattern was observed the sample was categorized as unmethylated (Figure.3 Lanes 10 and 12). Finally, samples that exhibited the digest banding pattern and also clearly had undigested PCR product were considered partially methylated. The methylation status of regions $1,2,4$, and 5 for all samples was determined using COBRA (Supplemental Figures S.1- S.11).

Methylation of region 3 was determined by MSP (Supplemental Figures S.12-S.15). A sample was deemed methylated if there was an amplicon produced by the methylated primer pair (Figure.4 Lane 5). Likewise, if the unmethylated primer pair amplified the sample it would then be categorized as unmethylated (Figure.4 Lanes 1, 2, 3 and 4). If amplicons were visible for both we determined that the sample must be composed of both methylated and unmethylated template and therefore we considered these to be partially methylated.

Methylation was more prevalent in lymphoid malignancies as compared to myeloid malignancies, solid tumors, and healthy lymphoid tissues (Figure.5). Specifically, $73.3 \%$ of all the regions analyzed in lymphoid malignancies were methylated. This is significantly higher than the percentage of regions methylated in myeloid malignances $(13.3 \%)$, solid tumors (34.3\%), and healthy tissues (1.4\%). This data demonstrates that the RUNDC3B CGI is a differentially methylated region (DMR) of the genome. Specifically this DMR is methylated more prominently in lymphoid malignancies. This DMR could be a useful biomarker for identifying lymphoid malignancies as it appears to characteristic of these samples.

Another distinguishing quality of the lymphoid malignancies was the amount of methylation across all of our regions of interest. We characterized samples exhibiting this 
increased methylation across the RUNDC3B CGI as methylation dense. Our data showed that the lymphoid malignancies exhibited the highest amount of methylation density. The average methylation density of the lymphoid malignancies was 0.67 which was substantially higher than myeloid malignancies (0.07), solid tumors $(0.23)$ and the unaffected cell lines $(0.007)$. This observed density of methylation in our lymphoid malignancies suggests that any potential epigenetic regulation may not be due to a single $\mathrm{CpG}$ site methylation event.

\section{Expression Analysis}

After analysis of the methylation we then determined the expression of $R U N D C 3 B$ to determine if there was evidence of epigenetic regulation. The healthy lymphoid tissue samples expressed $R U N D C 3 B$ (except for GM 05392); this indicates that the gene may be crucial to some biological function in healthy lymphoid tissues. Eleven samples resulted in no expression: Call 3, Nalm 6, Jurkat, DB, RL Daudi, Raji, A431, A549, WiDr, and GM 05392 (Supplemental Table S.1). The samples that expressed RUNDC3B most highly were Hela, MB 231, Mec-1, and KG-1 (Supplemental FigureS.1). Hela and MB 231 are solid tumors for cervical and breast carcinomas respectively. Mec-1 and KG-1 are for lymphoid and myeloid malignancies. These results are consistent with previous findings that $R U N D C 3 B$ is over expressed in breast cancer (Raguzet al2005).

When we grouped our data based on the expression of $R U N D C 3 B$ and the methylation density we observed some interesting trends (Table.7). First it was clear that no samples expressed $R U N D C 3 B$ if they also exhibited a methylation density score greater than .5. This observation is consistent with previous findings that methylation present in the $R U N D C 3 B$ CGI is associated with gene silencing. Furthermore, every sample that was 
categorized as methylation dense and failed to express $R U N D C 3 B$ was a lymphoid malignancy of either the bone marrow or the germinal center.

The expression data, of the lymphoid malignancies specifically, demonstrated some interesting trends when a wide scope was applied. The lymphoid malignancies analyzed in this study span several phases of tissue development. Lymphoid tissue development, as described earlier, occurs in several locations which includes lymph nodes and bone marrow for B-cells. The lymph node itself has two distinct zones; the mantle zone and germinal center. The cancers included in this study occur at every phase of B cell development from the bone marrow to the germinal center and finally to the peripheral blood. Interestingly, the expression of $R U N D C 3 B$ is repressed in the lymphoid malignancy cell lines originating from the germinal center and bone marrow (Supplemental Figure S.1). On the other hand, the cell lines of the mantle zone and peripheral blood expressed $R U N D C 3 B$.

The results of our statistical tests were very encouraging to our hypothesis, that aberrant methylation in lymphoid malignancies leads to the silencing of $R U N D C 3 B$. The analysis of our data through odds ratios helped us assess the strength of the association between $R U N D C 3 B$ expression and the methylation state of each of our regions of interest. To understand the results it is best to think of the outcome of an odds ratio as the strength of association of an outcome based on an event. In our analysis the outcome was the methylation status of our region of interest and the event wasRUNDC3B expression. The results of the odds ratios indicated a strong association between CGI methylation and $R U N D C 3 B$ expression. The p-values associated with these odds ratios indicated that these values are all statistically significant which established an association between methylation in the $R U N D C 3 B$ CGI and $R U N D C 3 B$ expression (Table.8). This association being; $R U N D C 3 B$ is 
repressed when methylation is present in the proximal CGI of the gene. Due to the fact that the odds ratio results were based on bivariate data, these tests offer a way to look for large scale trends between methylation and $R U N D C 3 B$ expression.

Additional trends were observed when the samples were arranged in decreasing expression of $R U N D C 3 B$ (Figure.6). For example, the samples that exhibit methylation are also the samples with the lowest expression of $R U N D C 3 B$. Spearman's correlations were calculated to identify the association between the methylation state of each region and the expression of $R U N D C 3 B$. The correlational coefficients between $R U N D C 3 B \triangle \mathrm{Ct}$ and the methylation status of the regions of interest indicated a strong association between these two variables (Table.9). This further supported our hypothesis that $R U N D C 3 B$ is repressed when methylation is present in the proximal CGI. Furthermore, we felt this analysis suited our data set better.

Additional ad hoc analysis was conducted to assess additional correlations in the data set. One trend we wanted to quantify was how the density of methylation associated with $R U N D C 3 B$ expression. Site-specific methylation versus density of methylation and the impact on gene expression is a topic that still isn't completely understood. Our findings suggested that density of methylation had a strong association with the repression of RUNDC3B (Table.9).The findings demonstrated that, in this instance, as methylation density increases the expression of $R U N D C 3 B$ decreases. Additionally we correlated the methylation status of the regions to each other. Region 5 methylation data had high correlative values with the other regions and the density of methylation across the CGI.Only region 5 demonstrated this high correlation between all other regions and methylation density. 
A critical aspect of our expression analysis was to verify that the methylation results we observed affected the expression of $R U N D C 3 B$ and not the expression of $A B C B 1$. By conducting the same association analysis using the $A B C B 1 \triangle \mathrm{Ct}$ values we were able to determine that methylation had no significant association with $A B C B 1$ expression (Supplemental Tables S.4 and S.5). This was an important conclusion because it demonstrated that the methylation we observed in lymphoid malignancies had no effect on a gene that has a large impact on the efficacy of cancer treatment. $A B C B 1$ may still be under the influence of other epigenetic modifications, but not methylation in our CGI of interest (Figure.7).

One short coming of this data was that the sample size $(n=20)$ essentially increases the error of our findings. The $95 \%$ confidence intervals of the odds ratios are an indication of this issue (Table.8). Essentially, removing a single piece of data could have significant impacts on the actual numbers we received. However, the strength of the associations we found is such that we have great confidence that our hypothesis is supported by the data. What our sample size hinders us from doing is concluding that any one region has a stronger association with $R U N D C 3 B$ expression than any other region. For example, region 5 has the highest correlation coefficient, but we are unable to conclude it has the strongest association with $R U N D C 3 B$ expression. This problem can be remedied by increasing the number of samples we analysis in this fashion. Also by determining if these findings hold true in patient samples analyzed using deep sequencing techniques.

\section{RUNDC3B DNA Sequence Analysis}

Several findings of our sequence analysis had interesting implications for $R U N D C 3 B$ and the proximal CGI. Aside from the RUN domain no other conserved protein domains 
have been identified based on the sequence of RUNDC3B. This doesn't allow us to make any novel conclusions about RUNDC3B function based on this approach. Analysis of the RUNDC3B CGI revealed it is 1486 base pairs and contains $132 \mathrm{CpG}$ sites. The CGI extends into the 5' untranslated region (UTR). Using these benchmarks we compared the full $R U N D C 3 B$ CGI and the RUNDC3B CGI without the 5' UTR to the CGIs annotated in species with $R U N D C 3 B$ homologs. The primate $R U N D C 3 B$ CGI sequences shared the highest homology withthe human CGI, but the other species was not as similar based on BLAST results. Analysis performed without the 5' UTR revealed that homology decreased between the human $R U N D C 3 B$ CGI. This suggested that the sequence of the humanRUNDC3BCGI was not well conserved across the annotated CGIs of other species. However, we resolved to determine if conservation of regulatory elements was present in these regions.

Two conserved TFBS were identified in the CGI for early growth response-3 (EGR3) and activating protein-2 (AP-2).The location of the EGR-3 site was located near the beginning of region 3; approximately 600 base pairs from the beginning of the CGI (Figure.8A). Since we established aberrant methylation could occur in region 3 we sought to investigate the EGR-3 site further. The sequence of the putative TFBS was obtained and then compared to the $R U N D C 3 B$ CGI in other species. This process revealed that the species with an annotated CGI demonstrated similar sequences to the human EGR-3 TFBS and also these sites were roughly in the same location relative to the $R U N D C 3 B$ gene body as observed in the human genome (Table.10). The conservation of the location of the putative TFBS suggested that these sequences may have a similar role in gene regulation. Each of the putative TFBS also all contained at least one CpG site. This denoted that aberrant methylation may occur directly on a TFBS (Figure.8). 
Another important feature of the EGR-3 TFBS is that it overlapped with an area of the genome that is DNaseI hypersensitive in humans. This denoted that the area of the genome is in an open chromatin state and therefore associated with active transcription. The presence of a TFBS in this region suggested that it could be a critical component of $R U N D C 3 B$ transcription. The presence of a CGI in the promoter region of $R U N D C 3 B$ and putative TFBS in an area associated with inducing gene expression lead us to believe this area of the genome has regulative capacities that may be affected by aberrant methylation.

EGR-3 is a zinc finger protein that has been identified to be involved in neuronal development, muscle development, and lymphocyte development. Thus a potential mechanism for $R U N D C 3 B$ silencing in lymphoid tissues may be that aberrant methylation in region 3 is interfering with regulatory elements such as EGR-3. Further analysis will be critical to elucidate if this interference is occurring in lymphoid malignancies.

\section{Alternate Pathway Analysis}

Recently, yeast-2-hybrid studies have revealed that RUNDC3B can interact with casein kinases, specifically the gamma sub family (CSNK1G1, CSNK1G2) (Vinayagamet al2011). These casein kinases have many roles in the regulation of Wnt signaling (Knippschildet al2005). Specifically they are responsible for phosphorylating the transmembrane proteins LRP5 and LRP6 (Bilicet al2007). This enables the formation of the signalosome that perpetuates Wnt signaling and $\beta$-catenin and other transcription factors to transcribe Wnt genes. Wnt activates Disheveled (Dvl) which, in turn, triggers LRP5/6 phosphorylation by CSNK1G. This active Dvl and phosphorylated LRP5/6 sequester frizzled (Fz), Axin, and Glycogen synthase kinase $3 \beta$ (GSK3 $\beta$ ) into a protein complex (Bilicet al2007). Outside of this complex these proteins act to select free $\beta$-catenin for protein 
degradation. Thus the formation of the signalosome is critical to canonical Wnt signaling and RUNDC3B may contribute to regulating one of the elements. This provides rationale to complete functional assays to determine if and how RUNDC3B interacts with components of the canonical Wnt signaling pathway.

\section{Preliminary Patient Data}

Our lab has been working on sequencing the methylome of ALL and the early precursor B cells. Using the data produced by sequencing ALL patients we can determine the extent to which our cell line findings hold true in actual patients. We have access to the methylome of 14 ALL patients and we determined 11 of these patients demonstrated methylation in our CGI of interest (79\%). Previous studies demonstrated similar percentages (87\%) in ALL patients where methylation was determined by CGI microarray data and validated using COBRA (Taylor et al 2007). Additionally, we accessed publically available reduced representation bisulfite sequencing data of 11 CLL patients. None of the patients observed displayed methylation in our CGI of interest. Although this is only a small percentage of the diseases included in our study, in the cases of ALL and CLL the patient data is consistent with our findings in cell lines. 


\begin{tabular}{|c|c|c|}
\hline Cell Line & Description & DNA $260 / 280$ \\
\hline Call 3 & ALL & 1.75 \\
\hline Nalm 6 & ALL & 2.03 \\
\hline Jurkat & ALL & 2.02 \\
\hline Mec-1 & CLL & 1.79 \\
\hline DB & DLBCL & 2.01 \\
\hline Granta & MCL & 1.95 \\
\hline RL & FL & 2.08 \\
\hline Raji & BL & 2.04 \\
\hline Daudi & $\mathrm{BL}$ & 2 \\
\hline U226B & MM & 1.98 \\
\hline KG-1a & AML & 1.98 \\
\hline KG-1 & AML & 1.88 \\
\hline MB 231 & Breast Carcinoma & 1.95 \\
\hline PC3 & Prostatic Small Cell Carcinoma & 1.84 \\
\hline Hela & Cervical Carcinoma & 1.95 \\
\hline A431 & Epidermal Carcinoma & 1.96 \\
\hline Melanoma & Epidermal Melanoma & 1.81 \\
\hline A549 & Lung Carcinoma & 2.01 \\
\hline WiDr & Colorectal Adenocarcinoma & 1.93 \\
\hline GM 06990 & B cells (unaffected) & 2.02 \\
\hline GM 05392 & B cells (unaffected) & 1.88 \\
\hline GM 00536 & B cells (unaffected) & 1.92 \\
\hline Cord Blood & B cells (unaffected) & 1.89 \\
\hline 4674 & B cells (unaffected) & 1.9 \\
\hline 4676 & B cells (unaffected) & 1.91 \\
\hline $\mathrm{KT}$ & $\mathrm{T}$ cells (unaffected) & 2.08 \\
\hline FO & B cells (unaffected) & 1.91 \\
\hline $\mathrm{HO}$ & B cells (unaffected) & 1.91 \\
\hline GI & B cells (unaffected) & 1.93 \\
\hline Male Bone Marrow & B cells (unaffected) & 1.94 \\
\hline Male Peripheral Blood \#1 & B cells (unaffected) & 1.94 \\
\hline Male Peripheral Blood \#2 & B cells (unaffected) & 1.93 \\
\hline Female Peripheral Blood & B cells (unaffected) & 1.94 \\
\hline
\end{tabular}

Table.1 Summary of cell lines and donor samples used in experiments. 33 cell lines and donor samples were used in our study. This includes lymphoid malignancies (9), myeloid malignancies (3), solid tumor cell lines (7), healthy B lymphocyte cell lines (3) and healthy donor samples (11). The disease state of each sample is included. The 260/280 values indicate the DNA samples used are of sufficient quality. A value of 1.8 or higher is optimal for further experiments using DNA. 


\begin{tabular}{|c|c|c|}
\hline Reagent & Amount & Reagent Concentration \\
\hline SAM & $4 \mu \mathrm{l}$ & $32 \mathrm{mM}$ \\
CpGMethyltransferase (M.SssI) & $4 \mu \mathrm{l}$ & $4000 \mathrm{units} / \mu \mathrm{l}$ \\
DNA Template & $2.5 \mathrm{ng}$ & \\
Water & up to $50 \mu \mathrm{l}$ & \\
\hline
\end{tabular}

Table.2SssI treatment reaction components and concentrations.

\begin{tabular}{|c|c|c|}
\hline Primer Name & Primer Sequence & Annealing Temperature $\left(\mathrm{C}^{\circ}\right)$ \\
\hline Region I F & 5'-GTTTTAGGATTTTGAGGGAGTAGTTTAG-3' & 56 \\
Region I R & 5'-CCCAAAAACTAATAAACAACAACAC-3' & 56 \\
Region II F & 5'-TTGTTGTTTATTAGTTTTTGGGAGG-3' & 56 \\
Region II R & 5'-CCCCTTACCTATAACCAAACTTTAAC-3' & 56 \\
Region III Methylated F & 5'-GGTTATTGGCGGTAGTTAGC-3' & 56 \\
Region III Methylated R & 5'-CGAAAAACCTCAACAAACGA-3' & 56 \\
Region III Unmethylated F & 5'-GGGTTTTGTCGTTGTTTTTC-3' & 56 \\
Region III Unmethylated R & 5'-CTTAAAAAAATTCTCGCTCGA-3' & 56 \\
Region IV F & 5'-GAGAATTTTTTTAAGTAGGTGTGG-3' & 60 \\
Region IV R & 5'-AAAACCCAAAACTCTCAACCC-3' & 60 \\
Region V F & 5'-GTGGAGAGGAGGAATTTGATTAT-3' & 56 \\
Region V R & 5'-AAACTAACACAAAATCCAAAACTAC-3' & 56 \\
\hline
\end{tabular}

Table.3RUNDC3B CGI primer sequences and PCR conditions. Primers with $56 \mathrm{C}^{\circ}$ annealing temperature were run with a touchdown 56 PCR program. Primers with $60 \mathrm{C}^{\mathrm{O}}$ annealing temperature were run with a touchdown 60 PCR program. PCR programs detailed in materials and methods. 
A.

\begin{tabular}{|c|c|c|}
\hline Reagent & Amount & Reagent Concentration \\
\hline Magnesium Chloride & $2.5 \mu \mathrm{l}$ & $25 \mathrm{mM}$ \\
PCR Buffer & $2.5 \mu \mathrm{l}$ & 10x concentrate \\
dNTPs & $0.5 \mu \mathrm{l}$ & $10 \mathrm{mM}$ \\
Primer & $0.75 \mu \mathrm{l}$ & $10 \mu \mathrm{M}$ \\
AmphiTaq Gold & $0.125 \mu \mathrm{l}$ & $5 \mathrm{units} / \mu \mathrm{l}$ \\
DNA template & $2-3 \mu \mathrm{l}$ & \\
Water & up to $25 \mu \mathrm{l}$ & \\
\hline
\end{tabular}

B.

\begin{tabular}{|c|c|c|}
\hline Reagent & Amount & Reagent Concentration \\
\hline NEB2 Buffer & $2.5 \mu \mathrm{l}$ & $10 \mathrm{x}$ concentrate \\
Bst-U1 & $1 \mu \mathrm{l}$ & 10,000 units $/ \mu 1$ \\
PCR product & $6 \mu \mathrm{l}$ & \\
Water & up to $25 \mu \mathrm{l}$ & \\
\hline
\end{tabular}

Table.4COBRA, MSP, and Bst-U1reatment reaction components and concentrations. A) The components and concentrations of PCR reactions, both COBRA and MSP. B) The components an concentrations of the Bst-U1 enzyme digest reaction.

\begin{tabular}{|c|c|c|}
\hline Reagent & Amount & Reagent Concentration \\
\hline Taqman Buffer & $4 \mu \mathrm{l}$ & $5 \mathrm{x}$ concentrate \\
Magnesium Acetate & $2.4 \mu \mathrm{l}$ & $25 \mathrm{mM}$ \\
dNTPs & $0.6 \mu 1(\mathrm{each})$ & $10 \mathrm{mM}$ \\
$\mathrm{r}^{\text {th }}$ polymerase & $0.8 \mu \mathrm{l}$ & $2.5 \mathrm{units} / \mu \mathrm{l}$ \\
Uracil-N-Glycosylase & $0.2 \mu \mathrm{l}$ & $1 \mathrm{units} / \mu \mathrm{l}$ \\
Taqman Primer/Probe & $1 \mu \mathrm{l}$ & $20 \mathrm{x}$ concentrate \\
RNA template & $40 \mathrm{ng}$ & \\
Water & up to $20 \mu \mathrm{l}$ & \\
\hline
\end{tabular}

Table.5RT-PCR reaction components and concentrations. 


$\begin{array}{ccc} & \text { Region X Methylated } & \text { Region X Unmethylated } \\ & \mathrm{a}=\# \text { of samples that were } & \mathrm{b}=\text { \# of samples that were } \\ R U N D C 3 B & \text { methylated and did not express } & \text { unmethylated and did not express } \\ \text { Silenced } & R U N D C 3 B & R U N D C 3 B \\ & \mathrm{c}=\# \text { of samples that were } & \mathrm{d}=\text { \# of samples that were } \\ \text { RUNDC3B } & \text { methylated and expressed } & \text { unmethylated and expressed } \\ \text { Expressed } & R U N D C 3 B & R U N D C 3 B\end{array}$

Table.6 Odds Ratio Illustration. For odds ratio analysis of our data each cell line that had methylation and $R U N D C 3 B / A B C B 1$ expression data was categorized in one of the above scenarios. Odds ratio is calculated by determining the odds of each of our categories then multiplying results as such $(a * d) /(b * c)$. Odds ratio, 95\% confidence interval and $p$ values were calculated using MedCalc software.

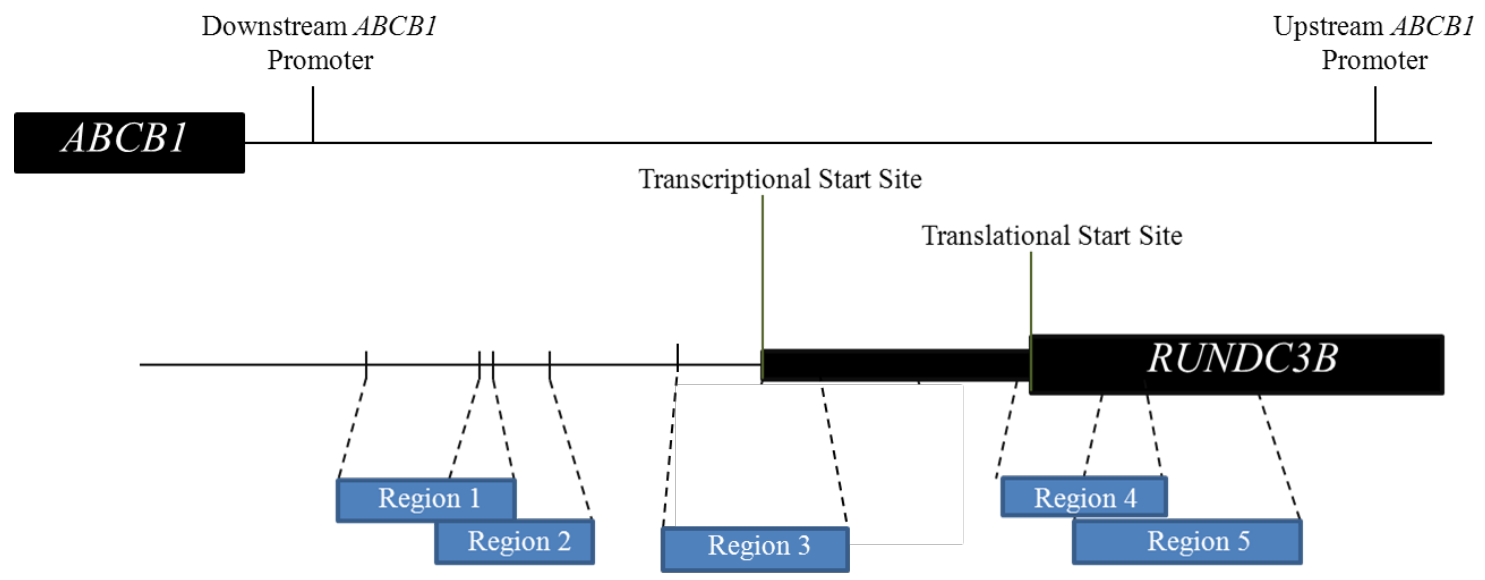

\section{CpG Island}

Figure.1 Promoter region of $R U N D C 3 B$ and the location of primers used in methylation assays. The promoter region of $R U N D C 3 B$ includes an annotated CGI (1486 bp). Five primers were designed to cover a large portion of this CGI (region 1: $300 \mathrm{bp}$; region 2: 176 bp; region 3: 375bp; region 4: $250 \mathrm{bp}$; region 5: $240 \mathrm{bp}$ ). The CGI is located so that it may impact the activity of the downstream promoter of $A B C B 1$, but not in the upstream promoter. 

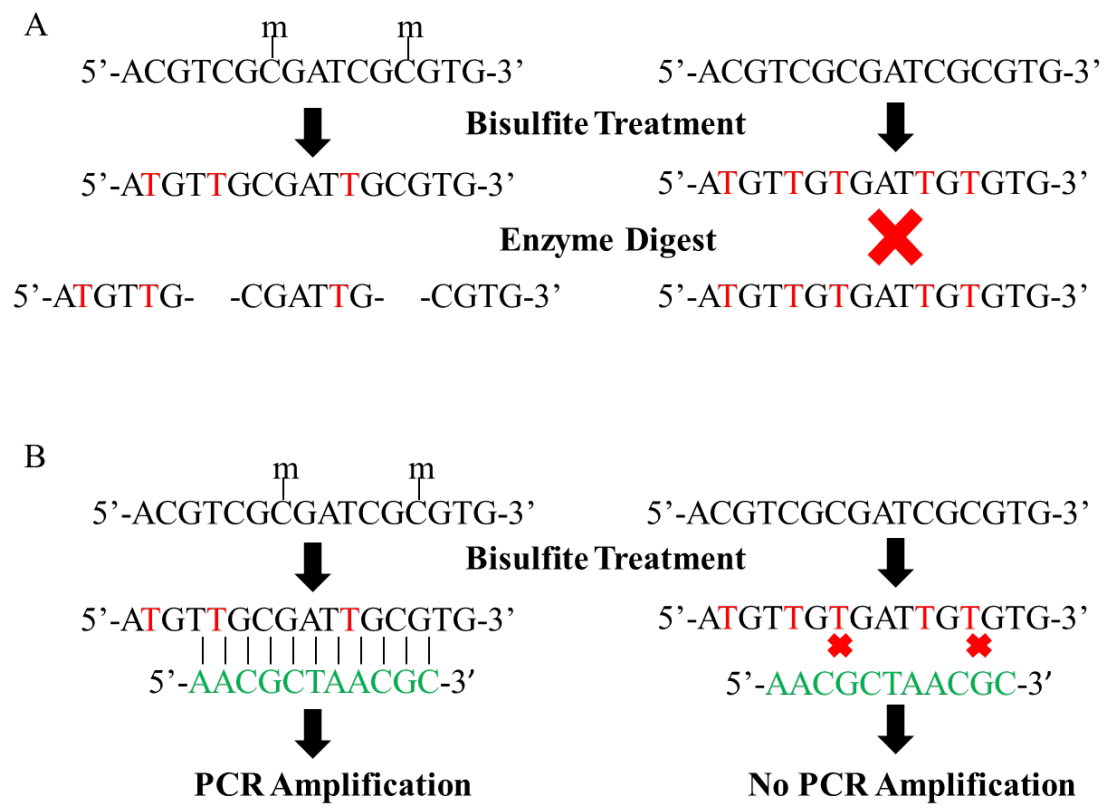

Figure.2 Schematic representation of COBRA and MSP assays. A) COBRA workflow includes bisulfite treatment that converts unmethylatedcytosines to thymines and creates differentiated sequence between methylated and unmethylated DNA. Enzyme digests can then be used to cut at CG sequences. Thus any unmethylated sequences will be left uncut by enzymes as these sequences will have been converted and will not be recognized by the enzyme. B) MSP workflow also utilizes bisulfite conversion. However, MSP utilizes differential primers to recognize methylated and unmethylated sequences. The primers designed to amplify methylated sequences are not complimentary to unmethylated sequences and vice versa because of the cytosine residue conversions. 


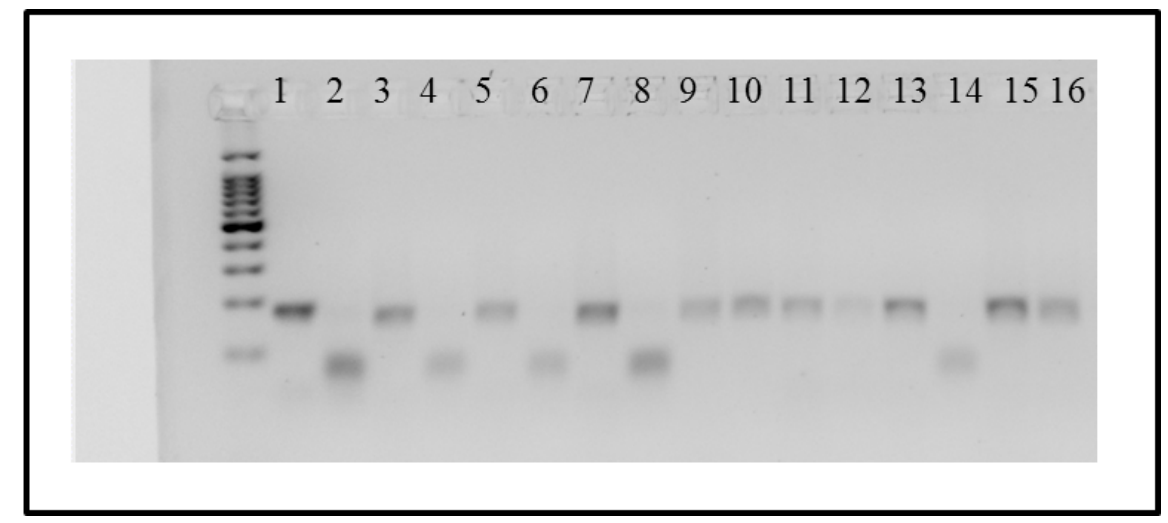

Figure.3 A representative sample of region 4 COBRA results. Each sample of the Region 4 COBRA using Bst-U1 is run in two lanes. The left lane is the result of the initial PCR. The right lane contains the result of the enzyme digest (ED). Samples are as follows: 1: Jurkat PCR;2: Jurkat ED;3: RL PCR;4: RL ED;5: Raji PCR;6: Raji ED;7: Daudi PCR;8: Daudi ED;9: WiDr PCR;10: WiDr ED;11: GM 06990 PCR;12: GM 06990 ED;13: SssI PCR;14: SssI ED;15: gDNA PCR;16: gDNA ED. The samples that exhibit no PCR product and show the banding patterns of the enzyme digest are considered methylated (Lanes 2, 4, 6, 8 and 14). The sample that show a band identical to the initial PCR product are considered unmethylated since no enzyme digest occurred (10, 12 and 16). Complete COBRA results available in Supplementary figures S.1-S.11.

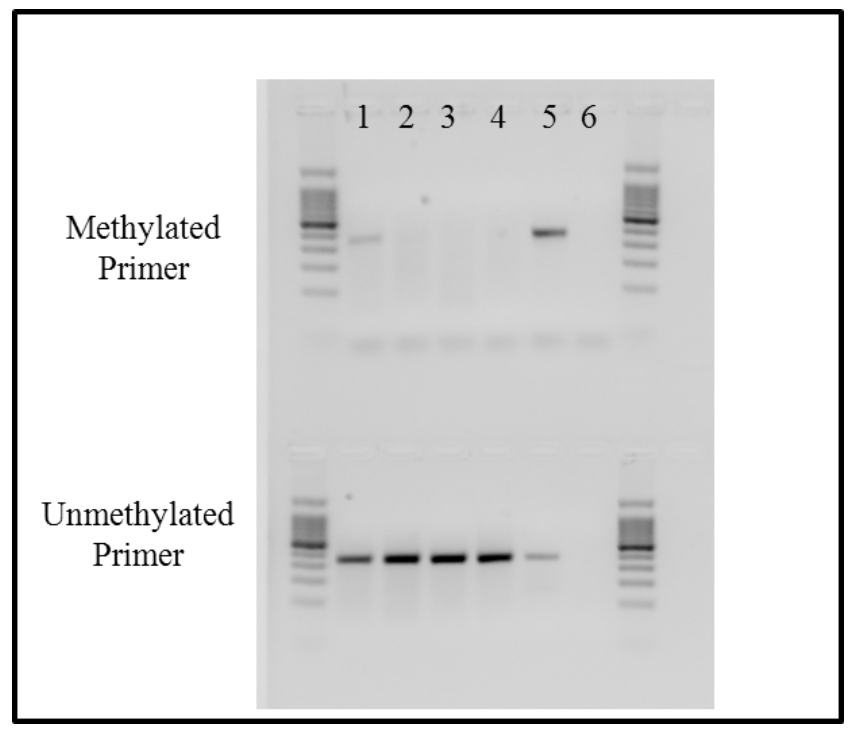

Figure.4 A representative sample of region 3 MSP results. A sample was categorized based on which primer set produced and amplicon. Methylated samples demonstrated by lane 5 and unmethylated by lanes 2, 3, and 4. A partially methylated sample is represented by lane 1.Lanes are as follows 1: U266B; 2: KG-1; 3: KG-1a; 4: gDNA; 5: SssI; 6: Water. Complete MSP results available in Supplementary figures S.12-S.15. 


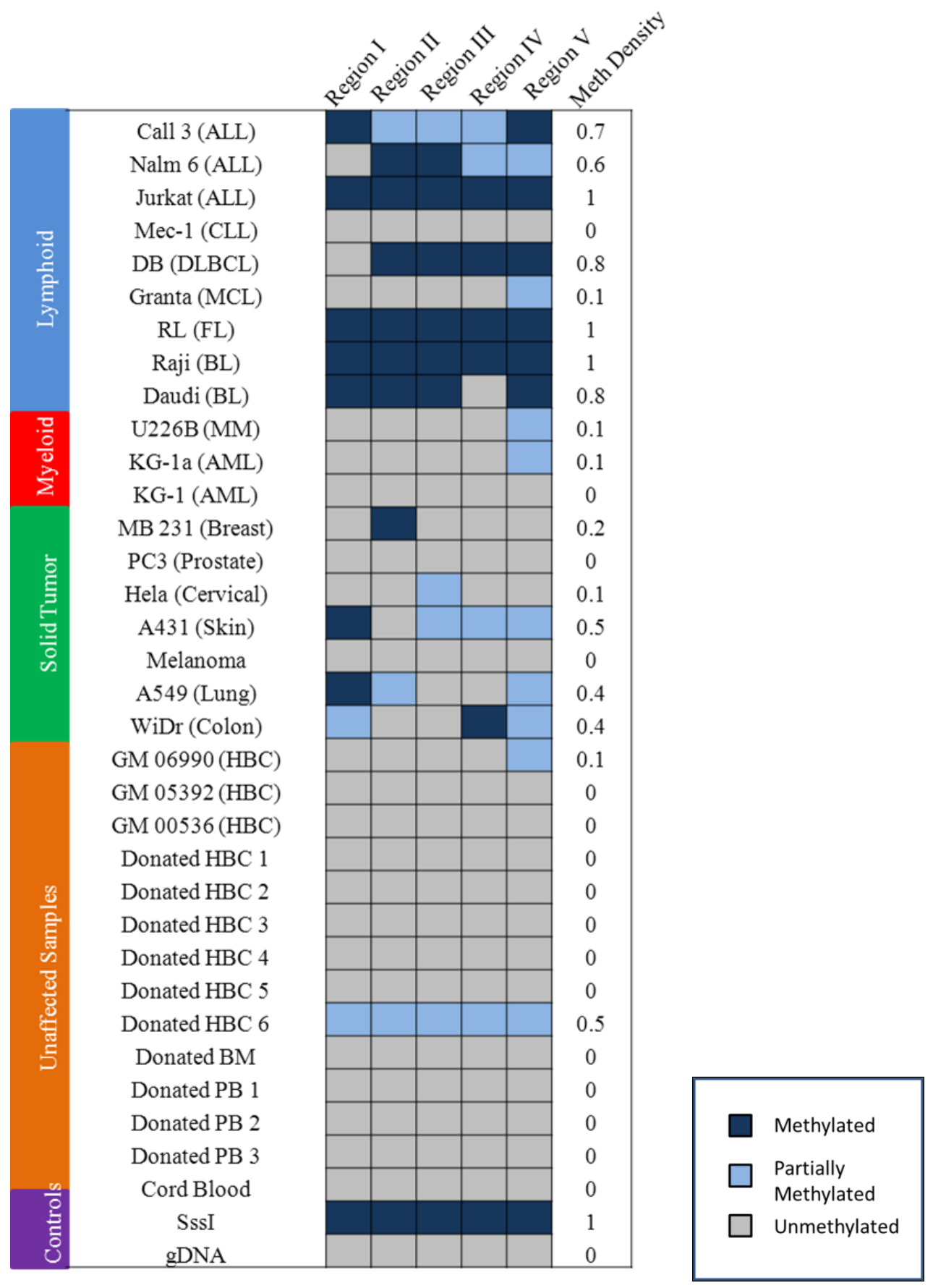

Figure.5 Summary of COBRA and MSP results in cancer cell lines, healthy cell lines, and healthy donor samples. The methylation status of the five regions in the RUNDC3B CGI was determined and the average of methylation across the entire RUNDC3B CGI (Meth Density). Dark blue squares denotea fully methylated region; light blue squares denote a partially methylated region, and grey squares denoteunmethylatedregions. Samples are organized based on tissue type and it is clear lymphoid malignancies display the highest amount of methylation. HBC denotes a healthy B cell sample. Methylation assay results available in Supplemental Figures S.1-S.15. 


\begin{tabular}{|c|c|c|c|}
\hline $\begin{array}{c}\text { RUNDC3B+ } \\
\text { Meth Density }>.5\end{array}$ & $\begin{array}{c}\text { RUNDC3B+ } \\
\text { Meth Density } \leq .5\end{array}$ & $\begin{array}{c}\text { RUNDC3B- } \\
\text { Meth Density }>.5\end{array}$ & $\begin{array}{c}\text { RUNDC3B- } \\
\text { Meth Density } \leq .5\end{array}$ \\
\hline & KG-1 (AML) & Call 3 (ALL) & A 431 (Skin) \\
& Hela (Cervical) & Nalm 6 (ALL) & WiDr (Colorectal) \\
& Mec-1 (CLL) & Jurkat (ALL) & A549 (Lung) \\
& Granta (MCL) & DB (DLBCL) & GM 05392 (HBC) \\
& MB 231 (Breast) & RL (FL) & \\
& GM 00536 (HBC) & Raji (BL) & \\
& GM 06990 (HBC) & Daudi (BL) & \\
& U226B (MM) & & \\
& Cord Blood (HBC) & & \\
& & & \\
\hline
\end{tabular}

Table.7 Methylation density of the RUNDC3B CGI is associated with expression of RUNDC3B.Based on the results of $R U N D C 3 B$ expression assays and the methylation density of the $R U N D C 3 B$ CGI the data was coupled. When organized as such it becomes clear that the vast majority of our data follow the trend that samples with high amounts of methylation fail to express $R U N D C 3 B$ and vice versa. No samples with high methylation density $(>.5)$ expressed $R U N D C 3 B$. All samples that fail to express $R U N D C 3 B$ and exhibit high methylation density are lymphoid malignancies.

$\begin{array}{cccc}\text { Region } & \text { OR } & 95 \% \text { CI } & \text { p-value } \\ 1 & 46.14 & 2.1-1028.8 & 0.016 \\ 2 & 21.33 & 1.8-251.3 & 0.015 \\ 3 & 21.33 & 1.8-251.4 & 0.015 \\ 4 & 46.14 & 2.1-1028.8 & 0.016 \\ 5 & 9 & 1.14-71.0 & 0.037\end{array}$

Table.8 Odds ratio results for associations between $R U N D C 3 B$ CGI methylation and RUNDC3B expression. The results of these statistical tests indicate that methylation in the CGI methylation associates strongly with repression of $R U N D C 3 B$. Statistically significant associations between presence of methylation and $R U N D C 3 B$ expression were determined by a p-value $<0.05$. 


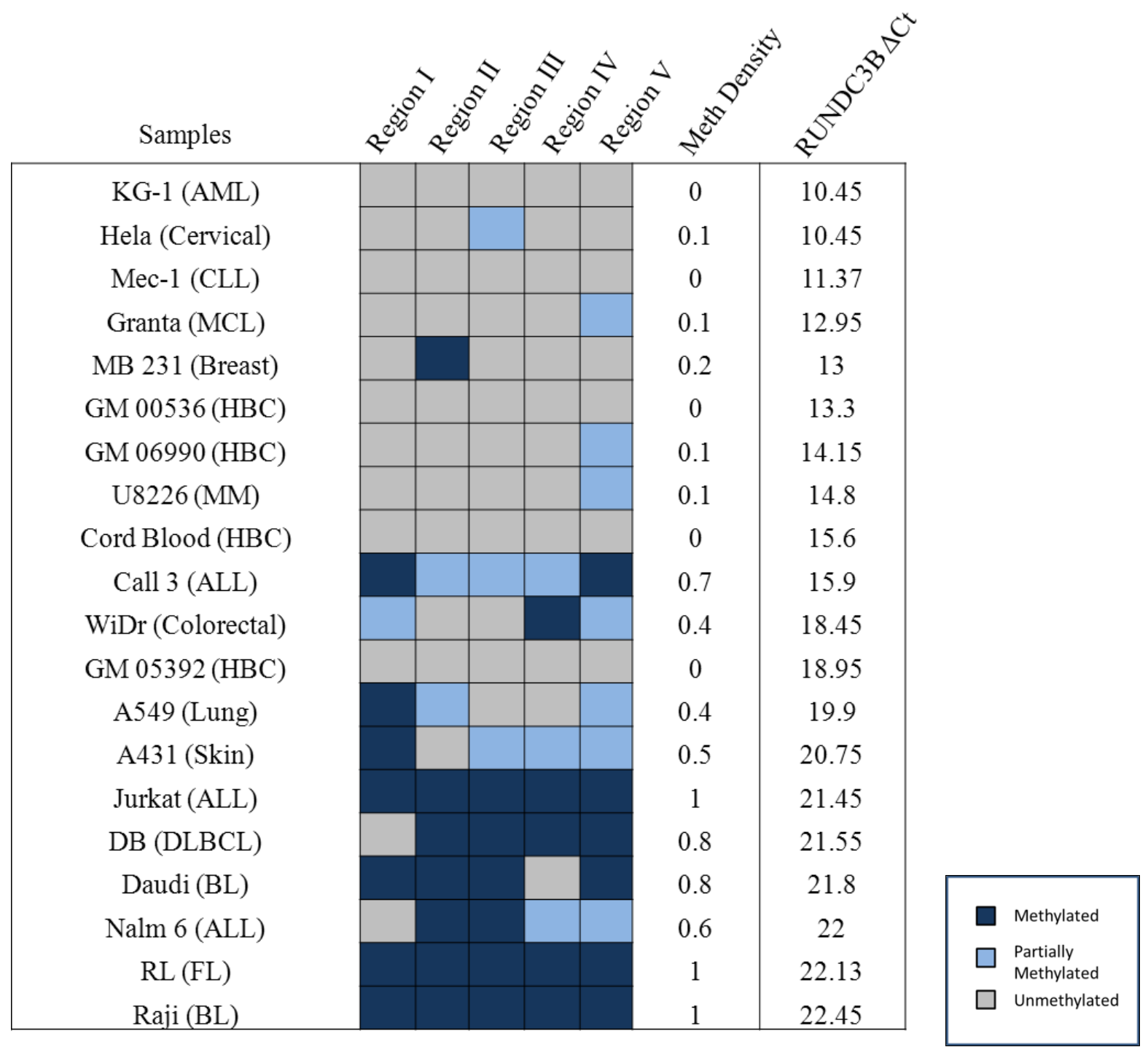

Figure.6Summary of methylation and expression assays. The cell line results are organized by decreasing $R U N D C 3 B$ expression. RUNDC3B $\triangle \mathrm{Ct}$ was determined by subtracting the GAPDH Ct from the RUNDC3B Ct for each sample. This normalizes the data so comparison between samples is possible. In conjunction with the methylation data, methylation density is included. Methylation density is calculated by adding the methylation status across all 5 samples (methylated sample $=1$; partially methylated $=.5$; unmethylated $=$ 0 ) and then dividing the total by 5 (the highest score possible). When the data is arranged this way it seems evident that methylated samples lead to reduced expression of $R U N D C 3 B$. 


\begin{tabular}{|c|c|c|}
\hline & $\begin{array}{c}\text { Correlation with } \\
R U N D C 3 B \\
\text { Expression (p-value) }\end{array}$ & $\begin{array}{c}\text { Correlation with } \\
\text { Region } 5 \text { Methylation } \\
\text { (p-values) }\end{array}$ \\
\hline Region 1 Methylation & $0.638(.002)$ & $0.705(.001)$ \\
\hline Region 2 Methylation & $0.701(.001)$ & $0.659(.001)$ \\
\hline Region 3 Methylation & $0.739(.000)$ & $0.738(.000)$ \\
\hline Region 4 Methylation & $0.698(.001)$ & $0.706(.001)$ \\
\hline Region 5 Methylation & $0.749(.000)$ & $1(.000)$ \\
\hline CGI Methylation Density & $0.799(.000)$ & $0.905(.000)$ \\
\hline
\end{tabular}

Table.9 Spearman's correlation results for associations between $R U N D C 3 B$ CGI methylation and $R U N D C 3 B$ expression. Statistically significant correlations established based on a p-value $<0.05$. It is clear a strong correlation exists between methylation across the $R U N D C 3 B$ CGI and $R U N D C 3 B$ expression. The results indicate that as methylation increases $R U N D C 3 B$ expression decreases. Furthermore, region 5 has high correlation with the other regions indicating it may be a potential biomarker.

A

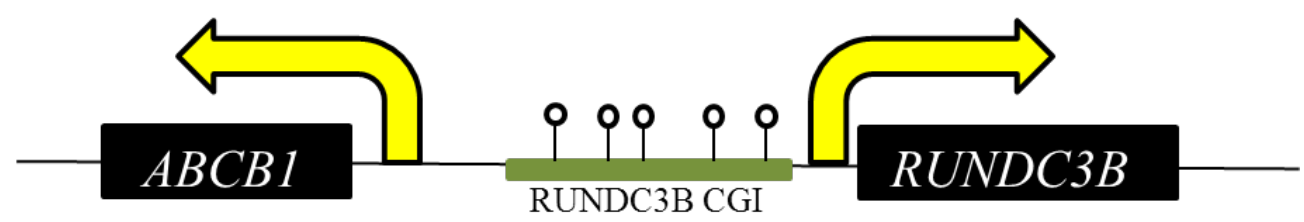

B

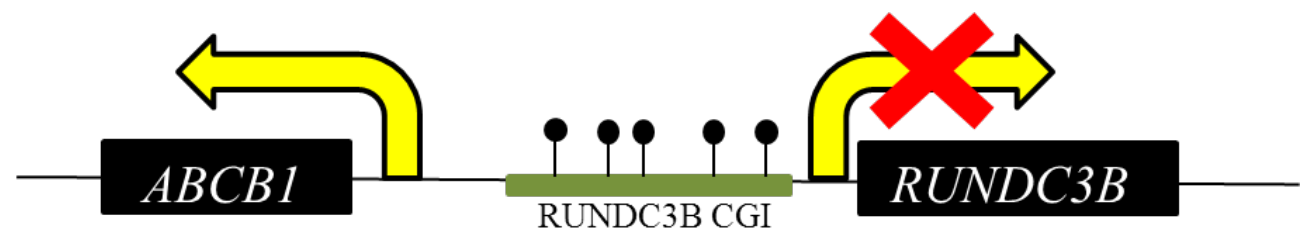

Figure.7 RUNDC3B CGI methylation and the effect on neighboring gene expression. A) The data suggest that if the RUNDC3B CGI is unmethylated both of the neighboring genes ( $A B C B 1$ and $R U N D C 3 B$ ) can be expressed. This seems to be the case in the wild type phenotype based on the results of normal B lymphocyte cell lines and healthy donor samples. B) Furthermore, when methylation is present across the RUNDC3B CGI neighboring gene expression is affected. $R U N D C 3 B$ has been shown to be silenced when this occurs, and $A B C B 1$ expression is left unchanged by this methylation pattern. 


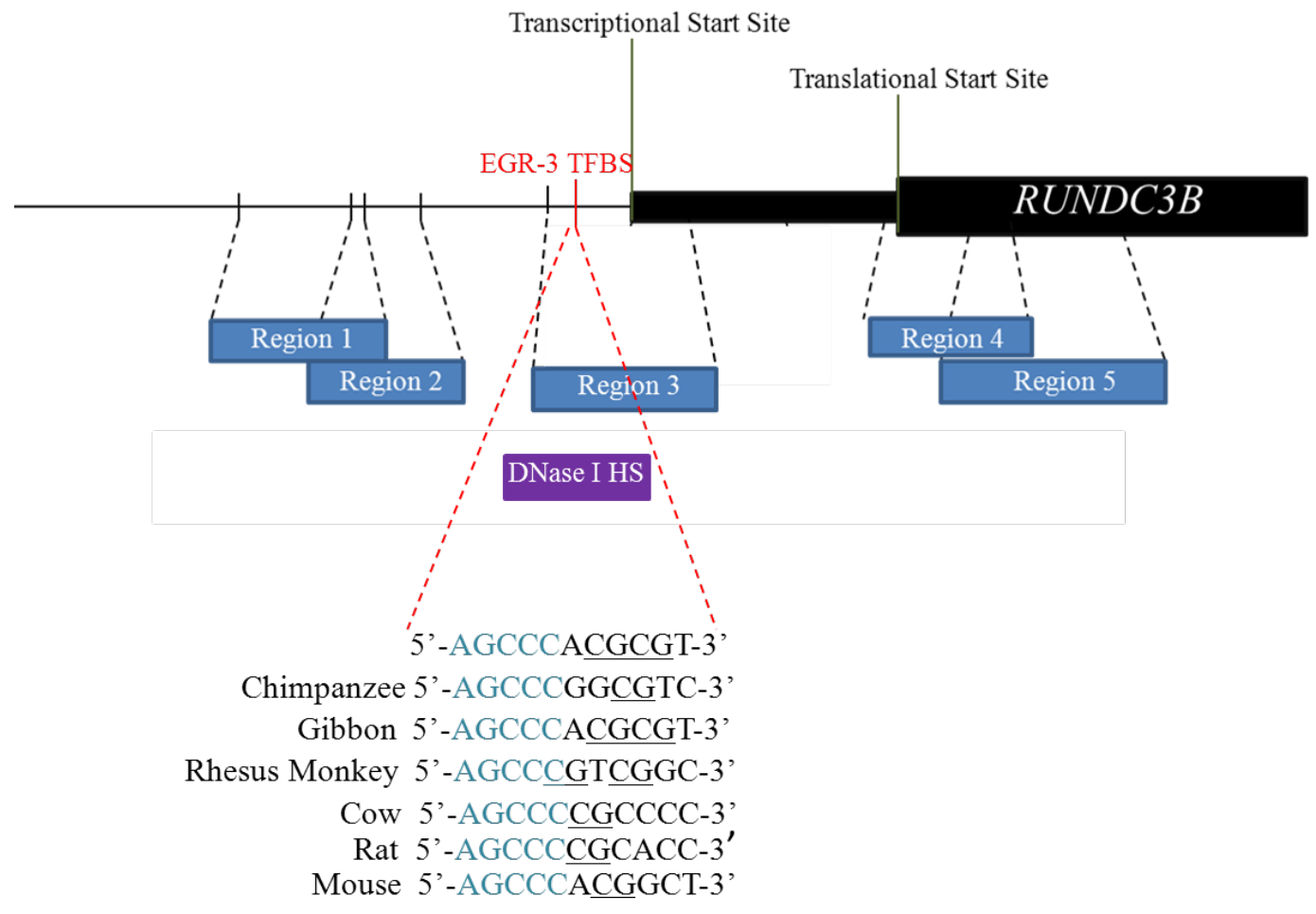

Figure.8 Regulatory elements of the RUNDC3B promoter region and conservation of putative TFBS across species. The promoter region of RUNDC3B contains a conserved EGR-3 TFBS (red) that occurs in a region of DNase I hypersensitivity (purple). The putative EGR-3 TFBS demonstrates similarity to sequences in other species. Light blue sequences indicate portions that are shared across all species and underlined sequences indicate CpGdinulceotides.

\begin{tabular}{|c|c|c|c|c|}
\hline & Location of Putative EGR-3 TFBS & Distance from 5 ' UTR & CGI Size & CpG Sites \\
\hline Human (Homo sapien ) & chr7: 87257559-87257570 & 159 bp & $1486 \mathrm{bp}$ & 132 \\
\hline Chimp (Pan Troglodytes) & chr7: 88150509-88150520 & $179 \mathrm{bp}$ & $1457 \mathrm{bp}$ & 139 \\
\hline Gibbon (Nomascus leucogenys ) & chr11: 18619869-18619880 & $138 \mathrm{bp}$ & $1507 \mathrm{bp}$ & 132 \\
\hline Rhesus Monkey (Macaca mulatta) & chr3: 130233741-130233752 & $123 \mathrm{bp}$ & $1444 \mathrm{bp}$ & 132 \\
\hline Mouse (Mus musculus ) & chr5: 8623044-8623055 & $92 \mathrm{bp}$ & 986 bp & 138 \\
\hline Rat (Rattus norvegicus) & chr4: 21689991-21690002 & $178 \mathrm{bp}$ & $1014 \mathrm{bp}$ & 85 \\
\hline Cow (Bos taurus ) & chr4: $33514640-33514651$ & $5 \mathrm{bp}$ & $1628 \mathrm{bp}$ & 100 \\
\hline
\end{tabular}

Table.10 Comparison of location of putative EGR-3 TFBS across species.Putative EGR-3 TFBS were identified and located in species with a CGI present in the promoter region of RUNDC3B. The chromosomal coordinates of the TFBS and the distance to the 5'UTR demonstrate the TFBS in conserved in several species. Details on the annotated CGIs are also presented. 


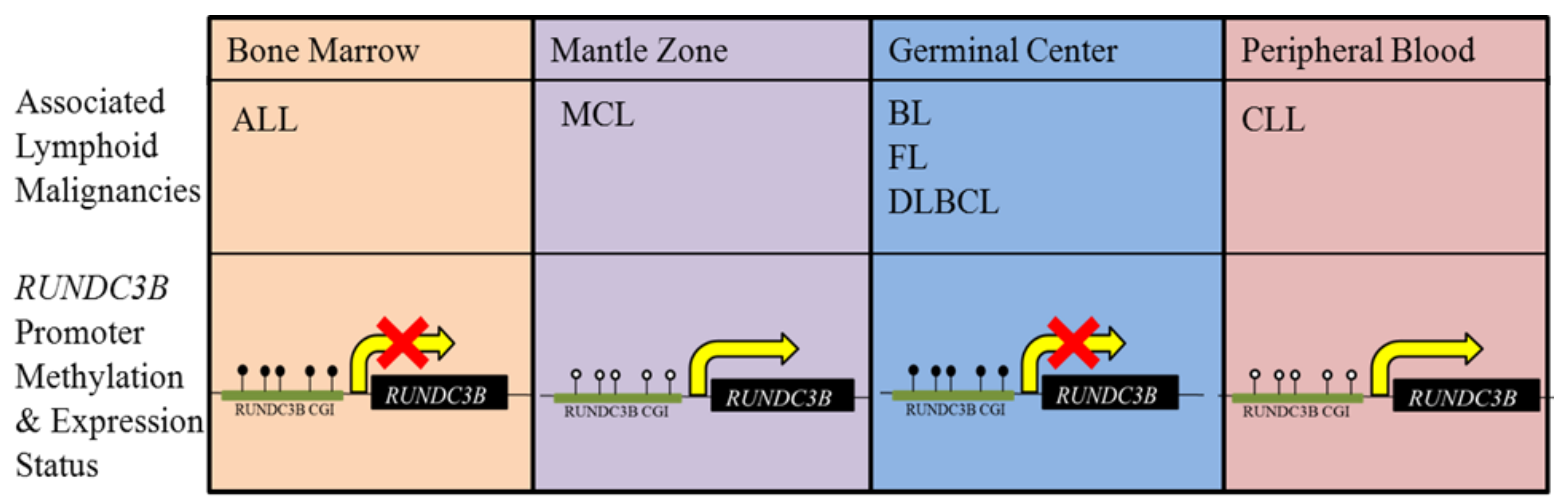

Figure.9 $R U N D C 3 B$ promoter methylation in phases of $B$ cell development.B cell development occurs across tissue types and distinct cancers occur during the process. Above it can be seen when these cancer types occur during development. Additionally, we observed differential states of methylation across the RUNDC3B CGI in these distinct regions. The trends we observed suggest that aberrant methylation and silencing of $R U N D C 3 B$ are characteristic of the cells of the bone marrow and germinal center.

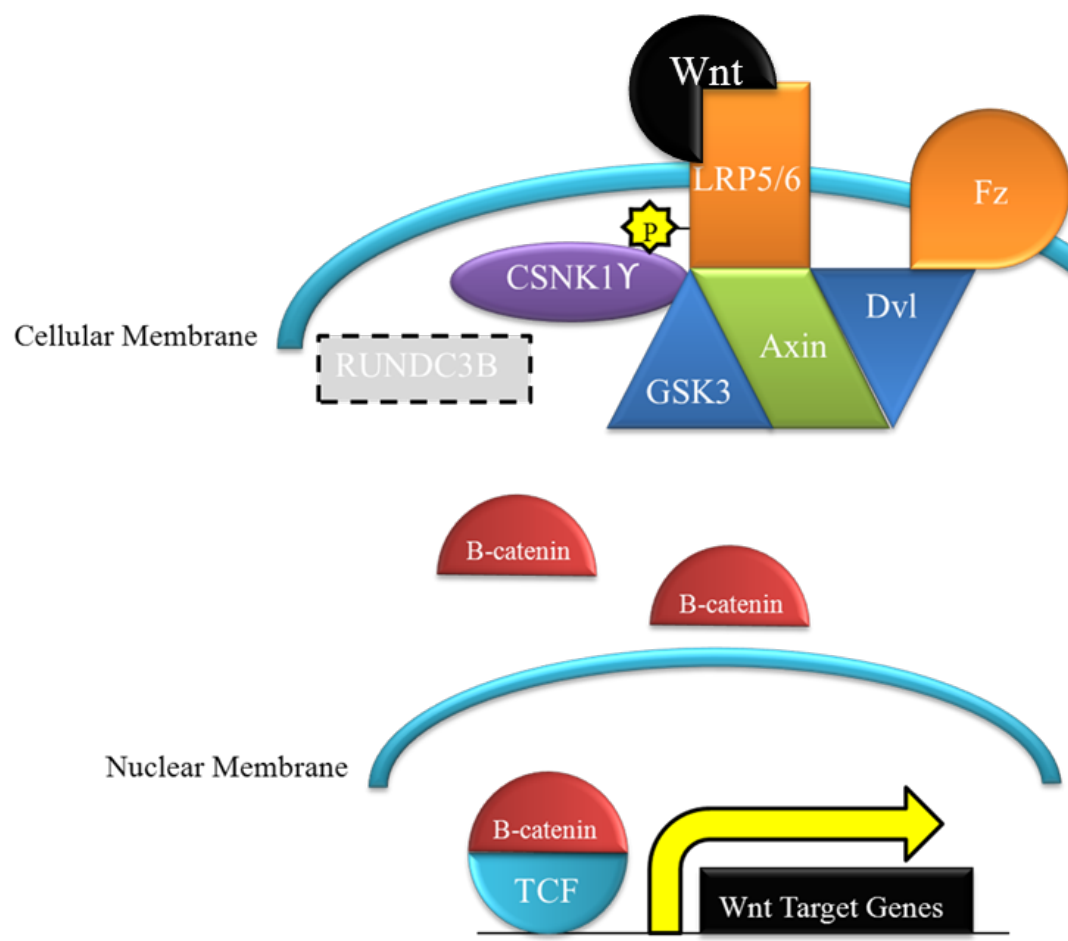

Figure.10 Aberrant silencing of $R U N D C 3 B$ may lead to increased expression of Wnt target genes. Due to the interaction of RUNDC3B with CSNK1G1/2, aberrant silencing may lead to downstream biological effects. If CSNK1G phosphorylated LRP5/6 in an unregulated manner $\beta$-catenin degradation machinery may be sequestered and therefore target Wnt genes would be expressed at an increased level 


\section{DISCUSSION}

Our work demonstrates that the aberrant methylation of $R U N D C 3 B$ occurs to a greater extent in lymphoid malignancies as compared to myeloid malignancies, various solid tumors, and healthy samples. Although aberrant methylation is also observed in several of the solid tumor cell lines, it is not to the extent observed in the lymphoid malignancies. Furthermore, the lymphoid malignancy samples also exhibit higher methylation density as they are the only samples to display methylation throughout the entire CGI. So not only is aberrant methylation more frequent in lymphoid malignancies, but the amount of methylation is also consistently greater. These observations provide support of investigating the use of $R U N D C 3 B$ CGImethylation as a biomarker for lymphoid malignancies. The data reveals the trend that this aberrant DNA methylation results in repression of $R U N D C 3 B$, and also this has no significant effect on $A B C B 1$ expression. Correlative results indicate that $R U N D C 3 B$ repression associates significantly with high levels of methylation, leading us to conclude that high methylation density in the $R U N D C 3 B$ CGI leads to silencing of the gene.

Further statistical analysis reveals the possibility of using the observed methylation as a biomarker. Region 5 has high correlations with the other regions and also with methylation density scores. What this suggests is that by determining the methylation state of region 5 we may be able to predict the methylation status of the other regions and the CGI as a whole. Furthermore, this would allow us to predict the expression of $R U N D C 3 B$. Gathering all of this knowledge from one COBRA region implies that region 5 methylation may be a useful biomarker for identifying lymphoid malignancies. While this is a promising finding, further experimentation is needed to verify that the COBRA result of region 5 is a useful biomarker for clinical use. 
Identifying biomarkers on a molecular level is very useful when dealing with leukemia. As aforementioned, MRD is a key issue in terms of assessing the efficacy of patient treatment. In leukemia patients MRD is a vital piece of information for determining whether or not continued treatment is needed. Since methylation of the region 5 is something that can be determined from a small (a few cells) amount of starting material it seems to follow that it could be a useful determinant of MDR. Molecular biomarkers can provide clinicians with greater confidence in the effects of cancer treatment which can spare patients from further therapy and potentially reduce relapse by detecting minute abnormalities.

Analysis of the RUNDC3B CGI reveals a conserved TFBS for EGR-3 across several species with a CGI in the promoter region of $R U N D C 3 B$. In these species, this TFBS is relatively in the same location and all sequences contain at least one $\mathrm{CpG}$ site. In the human genome this TFBS overlaps with areas of DNase I hypersensitivity. Aberrant methylation occurring in this region of genome may lead to the actual process of gene silencing. Direct methylation of the TFBS could prevent trans-acting regulatory elements, like EGR-3, from accessing the promoter region of the gene. Additionally, methylation in areas of DNase I hypersensitivity can lead to conformational changes to DNA (Lazaroviciet al2013). These changes can alter the accessibility of the sequence to proteins like transcription factors and reduce the expression of the gene.

Transcription regulating elements have been identified in the $R U N D C 3 B$ CGI. The activity of these elements can be adversely affected by DNA methylation. Therefore it would follow that aberrant methylation of this region of regulation may have far reaching and significant consequences. This finding doesn't necessarily validate that $R U N D C 3 B$ silencing 
results in tumorigenesis, but rather provides further evidence and support that we should continue to investigate this connection.

Upon further analysis, it appears that our data may be suggesting two different things. First, our methylation and expression data indicates methylation density is associated highly with $R U N D C 3 B$ silencing. Our sequence analysis, on the other hand, revealed a single section of the CGI could be responsible for altering gene expression. Is it possible both of these findings are true? One model of DNA methylation in disease can reconcile these opposing findings. DNA methylation seeding and spreading may offer a plausible solution. This model states that aberrant exonic methylation (seeding) can perpetuate into the promoter region of the gene (spread). Our findings show some trends that support this model may be active in our samples. Region 5 is within the exonic portion of gene and when this region was methylated there was a strong correlation that the sample was also methylation dense. Perhaps methylation of region 5 was the initial event and then this aberrant methylation spreads to the promoter region and then adversely affects the regulatory elements of the gene. Similar findings were exhibited in the estrogen receptor- $\beta$ gene in prostate cancer (Zhu et al2004). Methylation spreading is also supported by deep sequencing experiments in ALL and FL in patients (Taylor et al2007 b).

An interesting finding is that the lymphoid malignancies originating in the bone marrow and germinal center displayed aberrant methylation, whereas lymphoid malignancies pre and post germinal center did not (Figure.9). In addition, these samples failed to express $R U N D C 3 B$. This finding could be impactful on future diagnosis of these cancers. As of now it is not clear how aberrant methylation during these specific stages of B cell maturation may 
lead to cancer formation but warrants further analysis. Additionally it is not clear why some tissues may be at higher risk for methylation seeding and spreading.

We have demonstrated that aberrant methylation can disrupt $R U N D C 3 B$ expression and established a strong foundation to further investigate $R U N D C 3 B$ CGI hypermethylation as a contributor to the development of cancer in lymphoid tissues. The next step is to gather as much support as possible to link $R U N D C 3 B$ repression to established indicators of cancer pathogenesis. These indicators can include, but are not limited to, increased cell proliferation, abnormal cell differentiation, and/or repression of cell apoptosis.

Misregulation of Ras signaling through the loss of Rap2 activity no longer appears to be the outcome of $R U N D C 3 B$ silencing. In samples with aberrantly silenced RUNDC3B MAPK activity remained unchanged; contrary to initial RUNDC3B functional predictions. New potential interactions have also been established for RUNDC3B. Based on these findings, alternate pathways leading to cancer formation and/or development need to be established for further investigation. I would like to suggest that the canonical Wnt signaling pathway may be a pathway for further investigation of the physiological role of $R U N D C 3 B$ silencing in cancer formation. Recently interactions between RUNDC3B and casein kinase 1 gamma 1 and 2 (CSNK1G1/2) have been reported based on yeast 2 hybrid studies (Vinayagamet al2011).Both CSNK1G1 and CSNK1G2 are serine and threonine kinases involved in Wnt signaling. Further experimentation is necessary to confirm these interactions in lymphoid cells and thus strengthen the putative role of RUNDC3B in Wnt signaling.

Casein kinases work in the canonical signaling pathway in many ways. The gamma subfamily is in part responsible for perpetuating the signaling cascade. By interacting with 
LRP5 and LRP6 $\beta$-catenin is stabilized and therefore can act (with other molecules) as a transcription factor for Wnt target genes (Bilicet al2007). Wnt signaling has been demonstrated to be crucial to hematopoietic stem cell maintenance (Reyaet al2003). It is clear that in B cell progenitors, the cell type affected by ALL, Wnt signaling still serves crucial biological functions.

One study in particular has demonstrated that activated Wnt signaling may contribute to ALL development (Khan et al2007). Specifically, they demonstrated that over expression of Wnt genes can mediate the growth and survival of B cell progenitors afflicted with ALL. It is possible the silencing of $R U N D C 3 B$ we observed can lead to constitutively active betacatenin via unregulated casein kinase gamma activity (Figure.10). This could result in over expression of Wnt genes and as demonstrated could promote growth and survival in B cell progenitors. Additionally, it has been demonstrated $\beta$-catenin overexpression is present in several types of leukemia such as AML (Chung et al2002 and Simonet al 2005). This misregulation could begin or contribute to cancer development in the lymphoid tissues of the bone marrow.

Further experimentation is crucial to develop this theorized relationship of aberrant $R U N D C 3 B$ silencing and cancer formation in the bone marrow. It is important to elucidate the relationship between RUNDC3B and the CSNK1G1/2 in lymphoid tissue. This could be addressed through $R U N D C 3 B$ knockout experiments. Comparing these knockouts with healthy samples can reveal changes in canonical Wnt signaling activity. Protein assays like immunohistochemistry could also be useful in demonstrating that RUNDC3B colocalizes with CSNK1G1/2. Experiments that can identify phosphorylated LRP5/6 could also help 
determine activity of canonical Wnt signaling in tissues with differential methylation of the RUNDC3B CGI.

As our lab continues to process next generation sequencing data on the methylome of both ALL patients and unaffected B cells the findings of these experiments may be validated. If the trends of methylation and $R U N D C 3 B$ silencing can be generalized to patients we will have greater confidence that methylation of the $R U N D C 3 B$ CGI is a useful biomarker and potential contributor to pathogenesis. Next generation sequencing data of ALL patients may also contribute to demonstrating overactive Wnt signaling is present in those patients displaying aberrant $R U N D C 3 B$ CGI hypermethylation. We will be able to determine, at a transcript level, what pathways may be impacted.

In combination with a $R U N D C 3 B$ knockdown in healthy lymphocytes, deep RNA sequencing can reveal what other genes are being impacted. Comparing the results of RNAseq between the knockdown cells and control cells may reveal the impacts of $R U N D C 3 B$ silencing on genome-wide expression patterns. This set of experiments would produce a considerable amount of data and could reveal new avenues of research into the connection of $R U N D C 3 B$ silencing and tumorigenesis.

To conclude, we have illustrated that hypermethylation of the $R U N D C 3 B$ CGI leads to silencing of the gene. This DMR is methylated most prominently in lymphoid malignancies of the bone marrow and germinal center. The DMR may prove to be a useful biomarker to determine MRD in malignancies of the bone marrow and germinal center which include ALL, BL, FL and DLBCL. The RUNDC3B CGI is also well conserved in many vertebrate species indicating it may be an important regulatory element. We have yet to produce concrete evidence that this silencing leads to tumorigenesis, however we are 
confident that research should continue to find the evidence. There are promising avenues of investigation that we strongly believe should be followed. 


\section{BIBLIOGRAPHY}

Baylin SB and Herman JG. 2000. Epigenetics and loss of gene function in cancer. DNA Alterations in Cancer, Melanie Erlich, Eaton Publishing: 293-309.

Bilic J, Huang YL, Davidson G, Zimmermann T, Cruciat CM, Bienz M, and Niehrs C. 2007.Wnt Induces LRP6 Signalosomes and Promotes Dishevelled-DependentLRP6 Phosphorylation. Science 316: 1619-1622.

Bird, Adrian. 2002. DNA methylation patterns and epigenetic memory. Genes and Development 16: 6-21.

Chung EJ, Hwang SG, Nguyen PM, Lee S, Kim JS, Kim JW, Henkart PA, Bottaro DP, Soon L, Bonvini P, Lee SJ, Karp JE, Oh HJ, Rubin JS, and Trepel JB. 2002. Regulation of leukemic cell adhesion, proliferation, and survival by beta-catenin. Blood 100:982-990.

Denslow SA and Wade PA. 2007. The human Mi-2/NuRD complex and gene regulation. Oncogene 26: 5433-5438.

De Smet C, De Backer O, Faraoni I, Lurquim C, Brasseur F, and Boon T. 1996. The activation of human gene MAGE-1 in tumor cells is correlated with genome-wide demethylation. Proceedings of National Academy of Sciences 93: 7149-7153.

Duncan AW, Rattis FM, DeMascio LN, Congdon KL, Pazianos G, Zhao C, Yoon K, Cook JM, Willert K, Gaiano N, and Reya T. 2005. Integration of Notch and Wnt signaling in hematopoietic stem cell maintenance. Nature 6: 314-322.

Enokida H, Shiina H, Igawa M, Ogishima T, Kawakami T, Bassett WW, Anast JW, Li LC, Urakami S, Terashima M, Verma M, Kawahara M, Nakagawa M, Kane CJ, Carroll PR, and Dahiya R. 2004. CpGhypermethylation of MDR1 gene contributes to the pathogenesis and progression of human prostate cancer. Cancer Research 64: 5956-5962.

Esteve PO, Chin HG, Smallwood A, Feehery GR, Gangisetty O, Karpf AR, Carey MF, and Pradhan S.2006.Direct interaction between DNMT1 and G9a coordinates DNA and histonemethylation during replication. Genes\& Development 20:3089-3103.

Fardel O, Lecureur V, and Guillouzo A. 1996.The P-glycoprotein multidrug transporter. General Pharmacology: The Vascular System 27: 1283-1291. 
Holliday R and Pugh JE. 1975. DNA modification mechanisms and gene activity during development. Science 187: 226-232.

Johnson TB and Coghill RD. 1925.The discovery of the 5-methyl-cytodine in tuberculinic acid, the nucleic acid of Tubericle Bacillus. J Am Chem Soc.; 47: 2838-2844.

Jones PL, Veenstra GJC, Wade PA, Vermaak D, Kass SU, Landsberger N, Strouboulis J, and Wolffe AP. 1998. Methylated DNA and MeCP2 recruit histone deacetylaseto repress transcription. Nature Genetics 19: 187-191.

Joseph B, Mamatha G, Raman G, Shanmugam MP, and Kumaramanickavel G. 2004. Methylation status of RB1 promoter in indian retinoblastoma patients. Cancer Biology \& Treatment 3: 184-187.

Kahn NI, Bradstock KF, and Bendall LJ. 2007. Activation of Wnt/b-catenin pathway mediates growth and survival in B-cell progenitor acute lymphoblastic leukaemia. British Journal of Haematology 138: 338-348.

Knippschild U, Gocht A, Wolff S, Huber N, Lohler J, and Stoter M. 2005. The casein kinase 1 family: participation in multiple cellular processes in eukaryotes. Cellular Signalling 17: 675-689.

Kukimoto-Niino M, Takagi T, Akasaka R, Murayama K, Uchikubo-KamoT,Terada T, Inoue M, Watanabe S, Tanaka A, Hayashizaki Y, Kigawa T, Shirouzu M, an Yokoyama S. 2006. Crystal structure of the RUN domain in the rap2-interacting protein x. Journal of Biological Chemistry 281(42): 31843-31853.

Lazarovici A, Zhou T, Shafer A, Machado ACD, Riley TR, Sandstrom R, Sabo PJ, Lu Y, Rohs R, Stamatoyannopoulos JA, and Bussemaker HJ. 2013. Probing DNA shape and methylation state on a genomic scale with DNase I. Proceeding of the National Academy of Sciences 110: 6376-6381.

Lin CH, Hsieh SY, and Sheen IS. 2001. Genome-wide hypomethylation in hepatocellular carcinogenesis. Cancer Research 61:4238-4243.

Lyko F, Stach D, Brenner A, Stilgenbrauer S, Dohner H, Wirtz M, Wiessler M, and Schmitz OJ. 2004. Quantitative analysis of DNA methylation in chronic lymphocytic leukemia patients. Electrophoresis 25: 1530-1535.

Malhotra S and Kincade PW. 2009. Wnt-Related Molecules and Signaling Pathway Equilibrium in Hematopoiesis. Cell Stem Cell 4: 27-36. 
Noonan KE, Beck C, Holzmayer TA, Chin JE, Wunder JS, Andrulis IL, Gazdar AF, Willman CL, Griffith B, Von Hoff DD, and Roninson IB. 1990. Quantitative analysis of MDRI (multidrug resistance) gene expression in human tumors by polymerase chain reaction. PNAS 87: 7160-7164.

Prokhortchouk E and Defossez PA. 2008. The cell biology of DNA methylation in mammals. BiochimicaetBiophysicaActa 1783: 2167-2173.

Raguz S, Tamburo De Bella M, Slade MJ, Higgins CF, Coombes RC, and Yague E. 2005. Expression RPIP (rap2 interacting protein 9) is activated in breast carcinoma and correlates with poor prognosis. International Journal of Cancer 117: 934-941.

Reya T, Duncan AW, Ailles L, Domen J, Scherer DC, Willert K, Hintz L, Nusse R, Weissman IL. 2003. A role for wnt signaling in self-renewal of haematopoietic stem cells. Nature 423: 409-414.

Reya T and Clevers H. 2005 Wnt signaling in stem cells and cancer. Nature 434: 843850.

Robertson KD and Wolffe AP. 2000.DNA methylation in health and disease. Nature Reviews Genetics 1: 11-19.

Rountree, Michael. 2001. DNA methylation, chromatin structure, and cancer. Oncogene 20: 3156-3165.

Simon M, Grandage VL, Linch DC, and Kwhaja A. 2005.Constitutive activation of the Wnt/b-catenin signalling pathway in acute myeloid leukaemia. Oncogene 24: 2410-2420.

Snieder TW and Potter VR. 1969 Mehtylation of Mammalian DNA: Studies on Novikoff hematoma cells in tissue culture. Journal of Molecular Biology 42: 271-284.

Sulewska A, Niklinska W, Kozlowski M, Minarowski L, Naumnik W, Niklinski J, Dabrowska K, and Chyczewski L. 2007. DNA methylation in states of cell physiology and pathology. Folia HistochemicaetCytobiologica 45: 149-158.

Taylor KH, Pena-Hernandez KE, Davis JW, Arthur GL, Duff DJ, Shi H, Rahmatpanah FB, Sjahputera O, and Caldwell C. 2007 a. Large-scale CpG methylation analysis identifies novel candidate genes and reveals methylation hotspots in acute lymphoblastic leukemia. Cancer Research 67(6): 2617-2625.

Taylor KH, Kramer RS, Davis JW, Guo J, Duff DJ, Xu D, Caldwell CW, and Shi H. 2007 b.Ultradeep bisulfite sequencing analysis of DNA methylation patterns in multiple gene promoters by 454 sequencing. Cancer Research 67: 8511-8518. 
Toyota M, Kopecky KJ, Toyota MO, Jair KW, Wilman CL, and Issa JPJ. 2001. Methylation profiling in acute myeloid leukemia. Blood 97: 2823-2829.

Vinayagam A, Stelzl U, Foulle R, Plassmann S, Zenkner M, Timm J, Assmus HE, Andrade-Navarro MA, and Wanker EE. 2011. A directed protein network for investigating Intracellular signal transduction. Science Signaling 4: 1-11.

Wang MX, Wang HY, Zhao X, Srilatha N, Zheng D, Shi H, Ning J, Duff DJ, Taylor $\mathrm{KH}$, Gruner BA, and Caldwell CW. 2010. Molecular detection of b-cell neoplasms by specific DNA methylation biomarkers.Internatinal Journal of Clinical Experimental Pathology 3(3): 265-279.

Wang S, Zhang Z, Ying K, Chen JZ, Meng XF, Yang QS, Xie Y, and Mao YM. 2003. Cloning, expression, and genomic structure of a novel human rap2 interacting gene (RPIP9). Biochemical Genetics 41:13-25.

Wilson AS, Power BE, and Molloy PL. 2007. DNA hypomethylation and human diseases.BiochimicaetBiophysicaActa 1775: 138-162.

Zhu X, Leav I, Leung YK, Wu M, Liu Q, Gao Y, McNeal JE, and Ho SM. 2004. Dynamic regulation of estrogen receptor- $\beta$ expression by DNA methylation during prostate cancer development and metastasis. American Journal of Pathology 164: 2003-2012. 


\section{VITA}

Dane William Burmeister was born in Aurora, Illinois on April $5^{\text {th }} 1989$ to Lance and Kelly Burmeister. Dane began his higher education at Augustana College in Rock Island, Illinois in August of 2007. He graduated with a Bachelor of Arts with a major in Biological Sciences and a minor in Biochemistry in May of 2011. He began his work on a Master of Science in the Pathology and Anatomical Science Department in August of 2011. Upon completing this work he plans to pursue entering medical school. 


\section{APPENDIX}

\section{Supplemental Figures}

Figure S.1 COBRA Region 1 in cancer cell lines...................................57

Figure S.2 COBRA Region 2 in cancer cell lines...............................58

Figure S.3 COBRA Region 4 in cancer cell lines...................................58

Figure S.4 COBRA Region 5 in cancer cell lines..................................59

Figure S.5 COBRA Regions 1, 2, 4, and 5 in Cord Blood.............................59

Figure S.6 COBRA region 1 in cancer cell lines and donor samples...................60

Figure S.7 COBRA region 2 in cancer cell lines and donor samples..................60

Figure S.8 COBRA region 4 in cancer cell lines and donor samples..................61

Figure S.9 COBRA region 5 in cancer cell lines and donor samples.................61

Figure S.10 COBRA Region 1, 2, and 4 in healthy samples.........................62

Figure S.11 COBRA Region 5 in healthy samples.............................6 62

Figure S.12 MSP Region 3 in myeloid malignancy cell lines........................63

Figure S.13 MSP Region 3in lymphoid malignancy cell lines........................63

Figure S.14 MSP region 3in solid tumor cell lines...............................64

Figure S.15 MSP Region 3 in healthy samples................................64

\section{Supplemental Tables}

Table S.1 Real Time PCR Results for $R U N D C 3 B$ Expression.......................65

Table S.2 Real Time PCR Results for $A B C B 1$ Expression...........................66

Table S.3Real Time PCR Results for GAPDH Expression............................67

Table S.4Odds Ratios for association between $R U N D C 3 B$ CGI methylation and $A B C B 1$

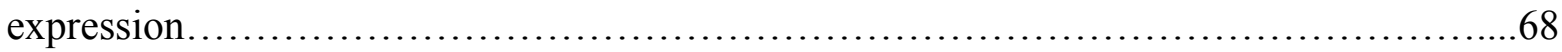


Table S.5Spearman correlation results for associations between $R U N D C 3 B$ CGI methylation

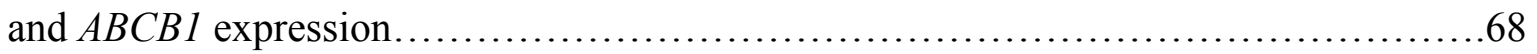




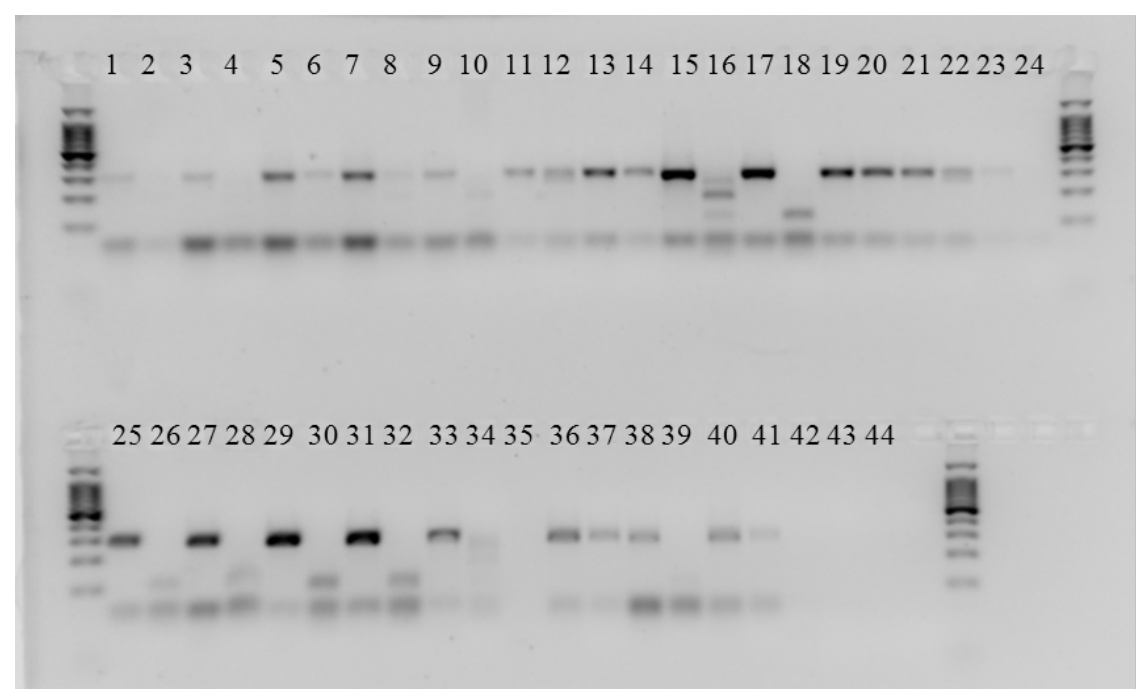

Figure S.1 COBRA Region 1 in cancer cell lines. All samples treated with Bst-U1 for enzyme digest (ED). Lanes are as follows: 1:Mec-1PCR; 2:Mec-1ED; 3:MB 231 PCR; 4:MB 231 ED; 5:PC3 PCR;6: PC3 ED; 7:Hela PCR;8:Hela ED;9:Call3 PCR;10: Cal13 ED;11: U226B PCR;12: U226B ED;13: KG-1a PCR;14: KG-1a ED;15: A431 PCR;16: A431 ED;17: A549 PCR;18: A549 ED;19: DB PCR;20: DB ED;21: Granta PCR;22: Granta ED;23: Nalm 6 PCR;24: Nalm 6 ED;25: Jurkat PCR;26: Jurkat ED;27: RL PCR;28: RL ED;29: Raji PCR;30: Raji ED;31: Daudi PCR;32: Daudi ED;33: WiDr PCR;34: WiDr ED;35: GM 06990 PCR;36: GM 06990 ED;37: SssI PCR;38: SssI ED;39: gDNA PCR;40: gDNA ED ;41: Water PCR;42: Water ED;43: Water 2 PCR;44: Water 2 ED. 


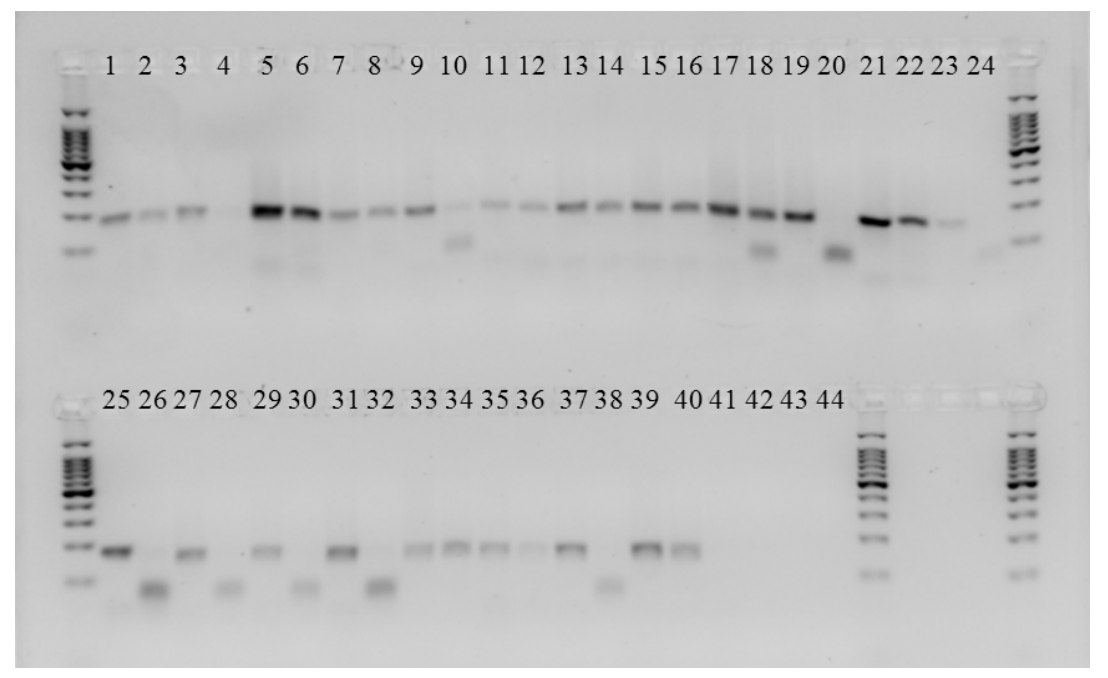

Figure S.2 COBRA Region 2 in cancer cell lines. All samples treated with Bst-U1 for enzyme digest (ED). Lanes are as follows: 1:Mec-1PCR; 2:Mec-1ED; 3:MB 231 PCR; 4:MB 231 ED; 5:PC3 PCR; 6: PC3 ED; 7:Hela PCR; 8:Hela ED; 9:Call3 PCR; 10: Call3 ED; 11: U226B PCR; 12: U226B ED; 13: KG-1a PCR; 14: KG-1a ED; 15: A431 PCR; 16: A431 ED; 17: A549 PCR; 18: A549 ED; 19: DB PCR; 20: DB ED; 21: Granta PCR; 22: Granta ED; 23: Nalm 6 PCR; 24: Nalm 6 ED; 25: Jurkat PCR; 26: Jurkat ED; 27: RL PCR; 28: RL ED; 29: Raji PCR; 30: Raji ED; 31: Daudi PCR; 32: Daudi ED; 33: WiDr PCR; 34: WiDr ED; 35: GM 06990 PCR; 36: GM 06990 ED; 37: SssI PCR; 38: SssI ED; 39: gDNA PCR; 40: gDNA ED ;41: Water PCR; 42: Water ED; 43: Water 2 PCR; 44: Water 2 ED.

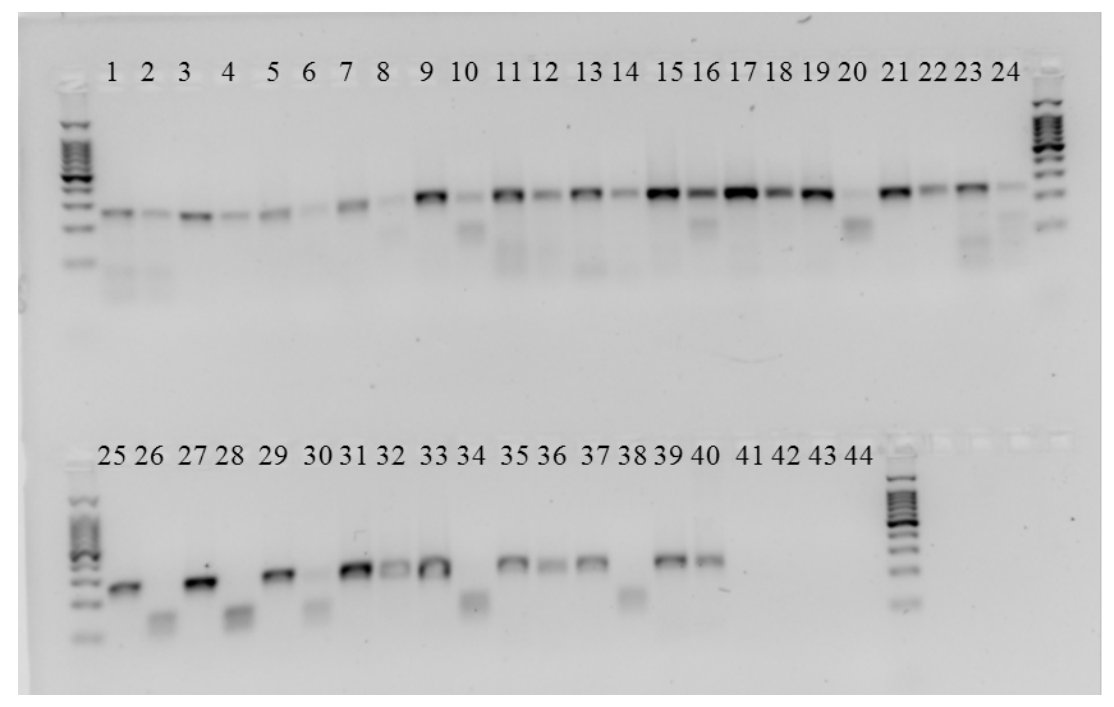

Figure S.3 COBRA Region 4 in cancer cell lines. All samples treated with Bst-U1 for enzyme digest (ED). Lanes are as follows: 1:Mec-1PCR; 2:Mec-1ED; 3:MB 231 PCR; 4:MB 231 ED; 5:PC3 PCR; 6: PC3 ED; 7:Hela PCR; 8:Hela ED; 9:Call3 PCR; 10: Call3 ED; 11: U226B PCR; 12: U226B ED; 13: KG-1a PCR; 14: KG-1a ED; 15: A431 PCR; 16: A431 ED; 17: A549 PCR; 18: A549 ED; 19: DB PCR; 20: DB ED; 21: Granta PCR; 22: Granta ED; 23: Nalm 6 PCR; 24: Nalm 6 ED; 25: Jurkat PCR; 26: Jurkat ED; 27: RL PCR; 28: RL ED; 29: Raji PCR; 30: Raji ED; 31: Daudi PCR; 32: Daudi ED; 33: WiDr PCR; 34: WiDr ED; 35: GM 06990 PCR; 36: GM 06990 ED; 37: SssI PCR; 38: SssI ED; 39: gDNA PCR; 40: gDNA ED ;41: Water PCR; 42: Water ED; 43: Water 2 PCR; 44: Water 2 ED. 


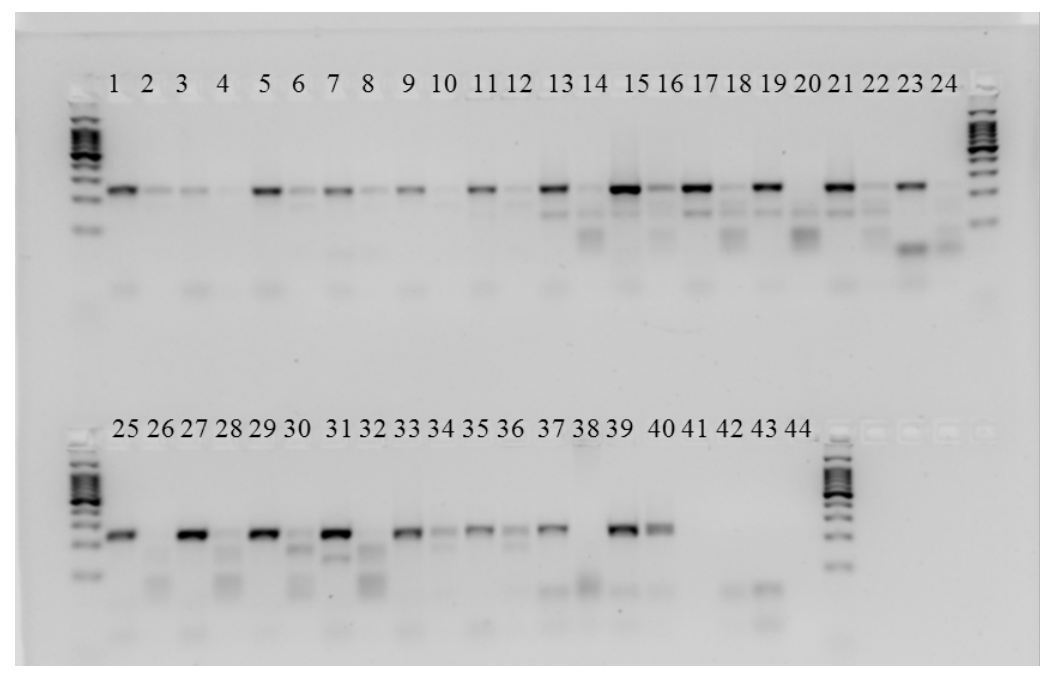

FigureS.4 COBRA Region 5 in cancer cell lines. All samples treated with Bst-U1 for enzyme digest (ED). Lanes are as follows: 1:Mec-1PCR; 2:Mec-1ED; 3:MB 231 PCR; 4:MB 231 ED; 5:PC3 PCR; 6: PC3 ED; 7:Hela PCR; 8:Hela ED; 9:Call3 PCR; 10: Call3 ED; 11: U226B PCR; 12: U226B ED; 13: KG-1a PCR; 14: KG-1a ED; 15: A431 PCR; 16: A431 ED; 17: A549 PCR; 18: A549 ED; 19: DB PCR; 20: DB ED; 21: Granta PCR; 22: Granta ED; 23: Nalm 6 PCR; 24: Nalm 6 ED; 25: Jurkat PCR; 26: Jurkat ED; 27: RL PCR; 28: RL ED; 29: Raji PCR; 30: Raji ED; 31: Daudi PCR; 32: Daudi ED; 33: WiDr PCR; 34: WiDr ED; 35: GM 06990 PCR; 36: GM 06990 ED; 37: SssI PCR; 38: SssI ED; 39: gDNA PCR; 40: gDNA ED ;41: Water PCR; 42: Water ED; 43: Water 2 PCR; 44: Water 2 ED.

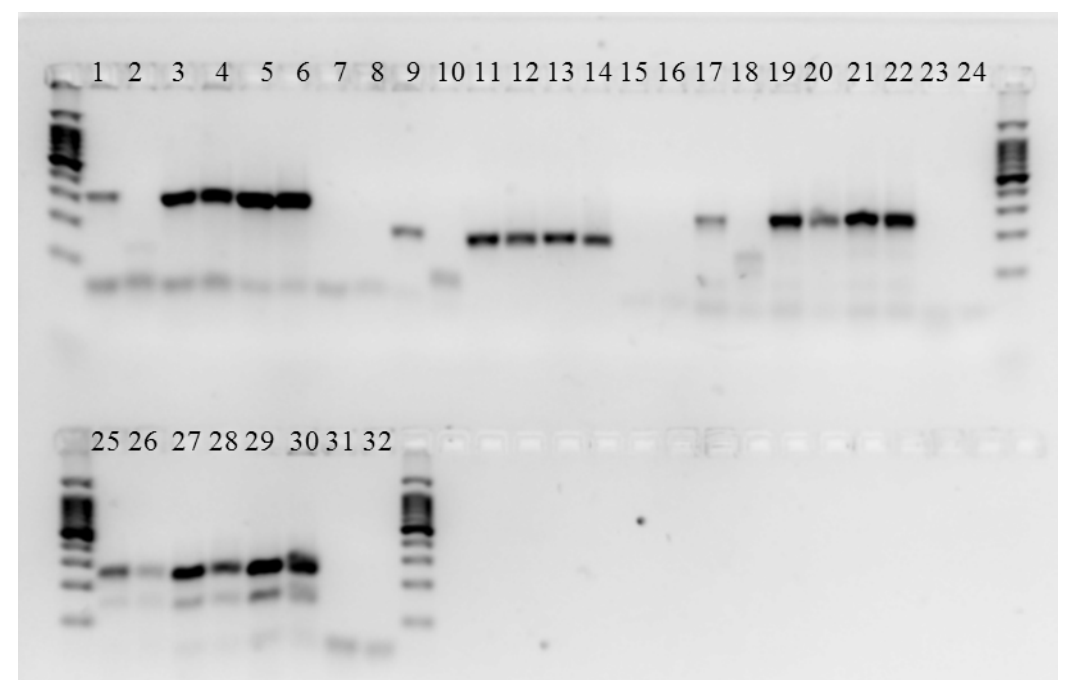

Figure S.5 COBRA Regions 1,2,4, and 5 in Cord Blood. All samples treated with Bst-U1 for enzyme digest (ED). Lanes 1-8 are COBRA of region 1, lanes 9-16 are region 2 samples, lanes 17-24 are region 4 samples, and lanes 25-32 are region 5 samples. Lanes are as follows: 1: SssI PCR; 2: SssI ED; 3: gDNA PCR; 4: gDNA PCR; 5: Cord Blood PCR; 6: Cord Blood ED; 7: Water PCR; 8: Water ED; 9: SssI PCR; 10: SssI ED; 11: gDNA PCR; 12: gDNA PCR; 13: Cord Blood PCR; 14: Cord Blood ED; 15: Water PCR; 16: Water ED; 17: SssI PCR; 18: SssI ED; 19: gDNA PCR; 20: gDNA PCR; 21: Cord Blood PCR; 22: Cord Blood ED; 23: Water PCR; 24: Water ED; 25: SssI PCR; 26: SssI ED; 27: gDNA PCR; 28: gDNA PCR; 29: Cord Blood PCR; 30: Cord Blood ED; 31: Water PCR; 32: Water ED. 


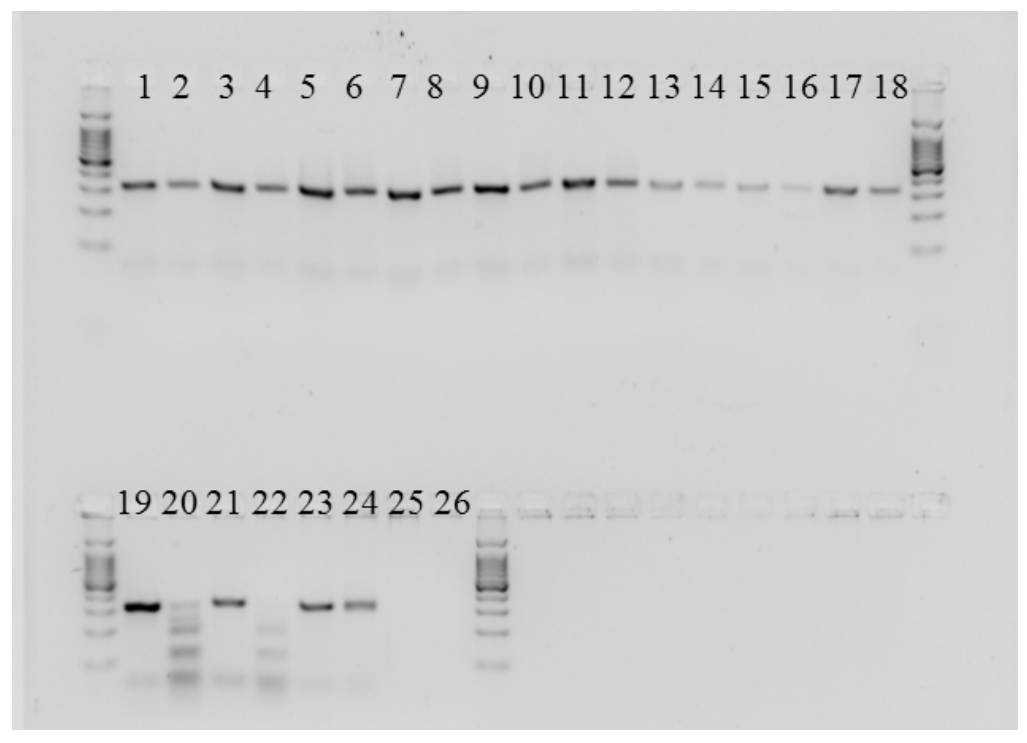

Figure S.6 COBRA region 1 in cancer cell lines and donor samples. All samples treated with Bst-U1 for enzyme digest (ED). Lanes are as follows: 1:GM 05392 PCR; 2:GM 05392 ED; 3:GM 00536 PCR; 4:GM 00536 ED; 5:KG-1 PCR; 6: KG-1 ED; 7:Melanoma PCR; 8:Melanoma ED; 9: 4674 PCR; 10: 4674 ED; 11: 4676 PCR; 12: 4676 ED; 13: KT PCR; 14: KT ED; 15: FO PCR; 16: FO ED; 17: HO PCR; 18: HO ED; 19: GI PCR; 20: GI ED; 21: SssI PCR; 22: SssI ED; 23: gDNA PCR; 24: gDNA ED; 25: Water PCR; 26: Water ED.

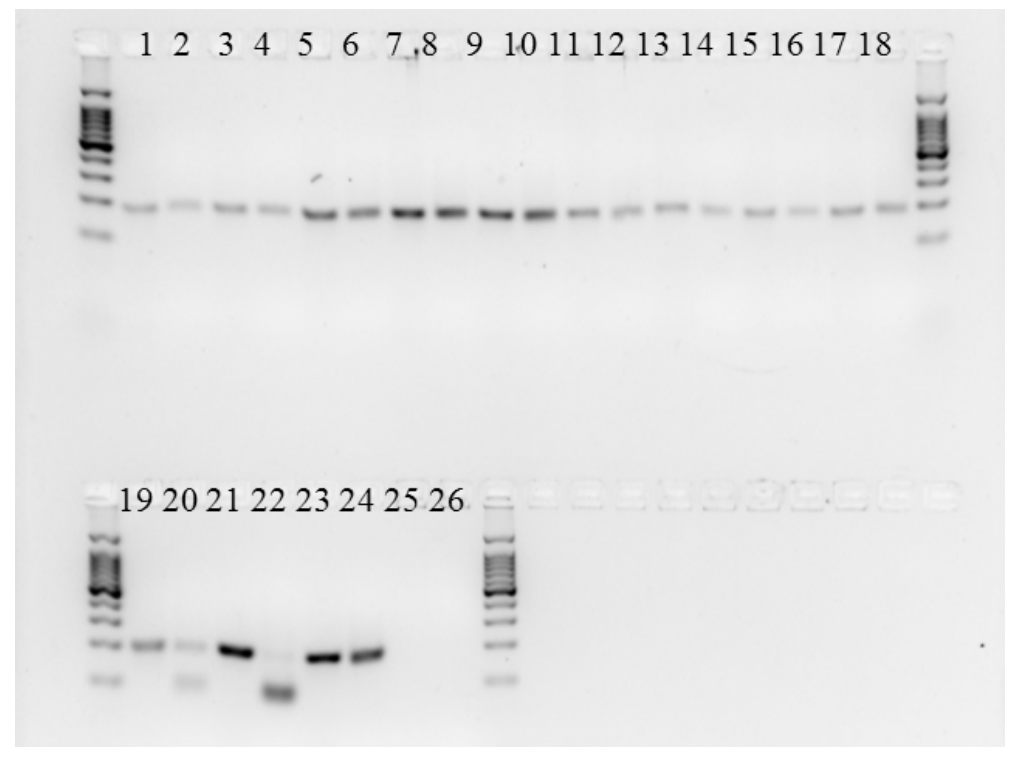

Figure S.7 COBRA Region 2 in cancer cell lines and donor samples. All samples treated with Bst-U1 for enzyme digest (ED). Lanes are as follows: 1:GM 05392 PCR; 2:GM 05392 ED; 3:GM 00536 PCR; 4:GM 00536 ED; 5:KG-1 PCR; 6: KG-1 ED; 7:Melanoma PCR; 8:Melanoma ED; 9: 4674 PCR; 10: 4674 ED; 11: 4676 PCR; 12: 4676 ED; 13: KT PCR; 14: KT ED; 15: FO PCR; 16: FO ED; 17: HO PCR; 18: HO ED; 19: GI PCR; 20: GI ED; 21: SssI PCR; 22: SssI ED; 23: gDNA PCR; 24: gDNA ED; 25: Water PCR; 26: Water ED 


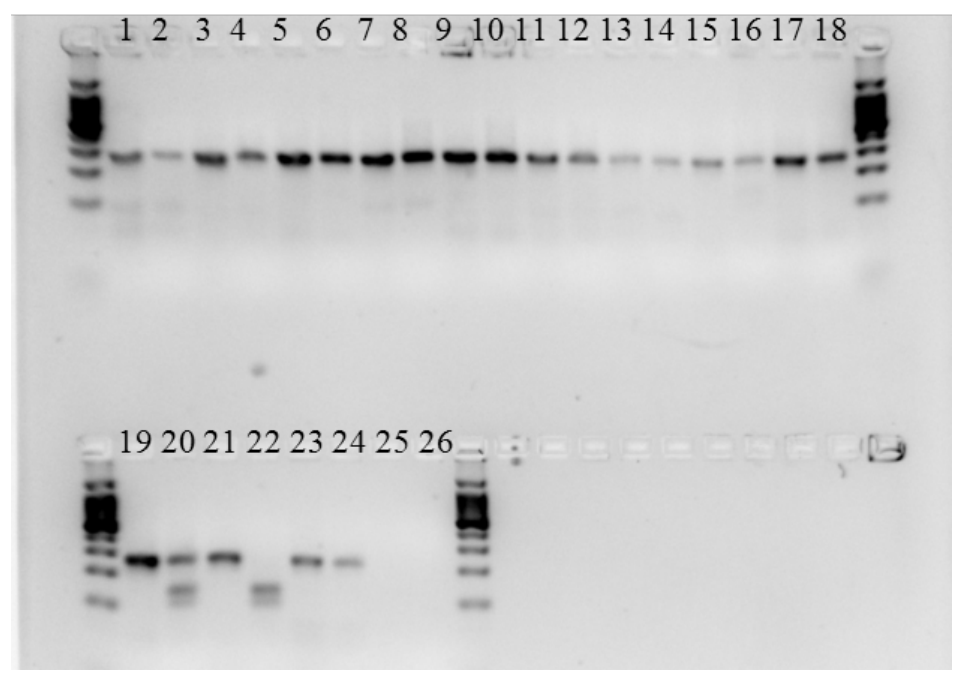

Figure S.8 COBRA Region 4 in cancer cell lines and donor samples. All samples treated with Bst-U1 for enzyme digest (ED). Lanes are as follows: 1:GM 05392 PCR; 2:GM 05392 ED; 3:GM 00536 PCR; 4:GM 00536 ED; 5:KG-1 PCR; 6: KG-1 ED; 7:Melanoma PCR; 8:Melanoma ED; 9: 4674 PCR; 10: 4674 ED; 11: 4676 PCR; 12: 4676 ED; 13: KT PCR; 14: KT ED; 15: FO PCR; 16: FO ED; 17: HO PCR; 18: HO ED; 19: GI PCR; 20: GI ED; 21: SssI PCR; 22: SssI ED; 23: gDNA PCR; 24: gDNA ED; 25: Water PCR; 26: Water ED.

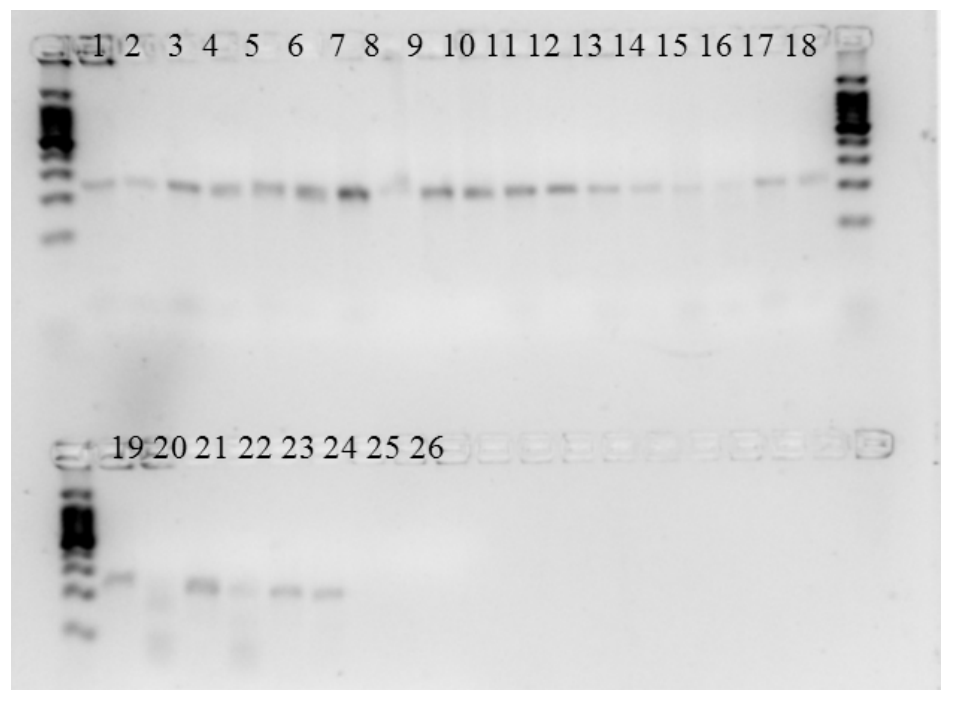

Figure S.9 COBRA Region 5 in cancer cell lines and donor samples. All samples treated with Bst-U1 for enzyme digest (ED). Lanes are as follows: 1:GM 05392 PCR; 2:GM 05392 ED; 3:GM 00536 PCR; 4:GM 00536 ED; 5:KG-1 PCR; 6: KG-1 ED; 7:Melanoma PCR; 8:Melanoma ED; 9: 4674 PCR; 10: 4674 ED; 11: 4676 PCR; 12: 4676 ED; 13: KT PCR; 14: KT ED; 15: FO PCR; 16: FO ED; 17: HO PCR; 18: HO ED; 19: GI PCR; 20: GI ED; 21: SssI PCR; 22: SssI ED; 23: gDNA PCR; 24: gDNA ED; 25: Water PCR; 26: Water ED 


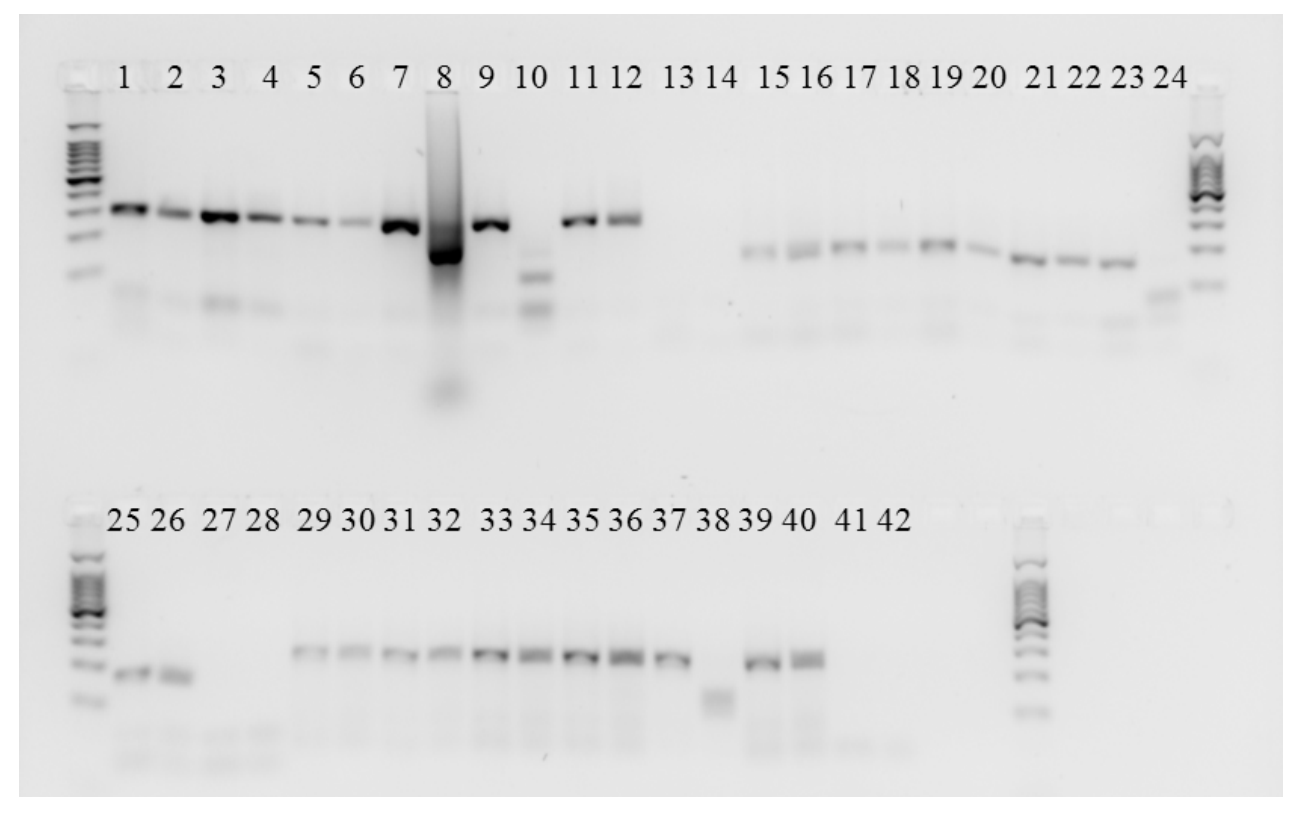

Figure S.10 COBRA Region 1,2, and 4 in healthy samples. All samples treated with Bst-U1 for enzyme digest (ED). Lanes 1-14 are COBRA of region 1, lanes 15-28 are region 2 samples, and lanes 29-42 are region 4 samples. Lanes are as follows: 1: Male Bone Marrow PCR; 2: Male Bone Marrow ED; 3: Male Peripheral Blood 1 PCR; 4: Male Peripheral Blood 1 PCR; 5: Male Peripheral Blood 2 PCR; 6: Male Peripheral Blood 2 ED; 7: Female Peripheral Blood; 8: Female Peripheral Blood ED; 9: SssI PCR; 10: SssI ED; 11: gDNA PCR; 12: gDNA PCR; 13: Water PCR; 14: Water ED; 15: Male Bone Marrow PCR; 16: Male Bone Marrow ED; 17: Male Peripheral Blood 1 PCR; 18: Male Peripheral Blood 1 PCR; 19: Male Peripheral Blood 2 PCR; 20: Male Peripheral Blood 2 ED; 21: Female Peripheral Blood; 22: Female Peripheral Blood ED; 23: SssI PCR; 24: SssI ED; 25: gDNA PCR; 26: gDNA PCR; 27: Water PCR; 28: Water ED; 29: Male Bone Marrow PCR; 30: Male Bone Marrow ED; 31: Male Peripheral Blood 1 PCR; 32: Male Peripheral Blood 1 PCR; 33: Male Peripheral Blood 2 PCR; 34: Male Peripheral Blood 2 ED; 35: Female Peripheral Blood; 36: Female Peripheral Blood ED; 37: SssI PCR; 38: SssI ED; 39: gDNA PCR; 40: gDNA PCR; 41: Water PCR; 42: Water ED.

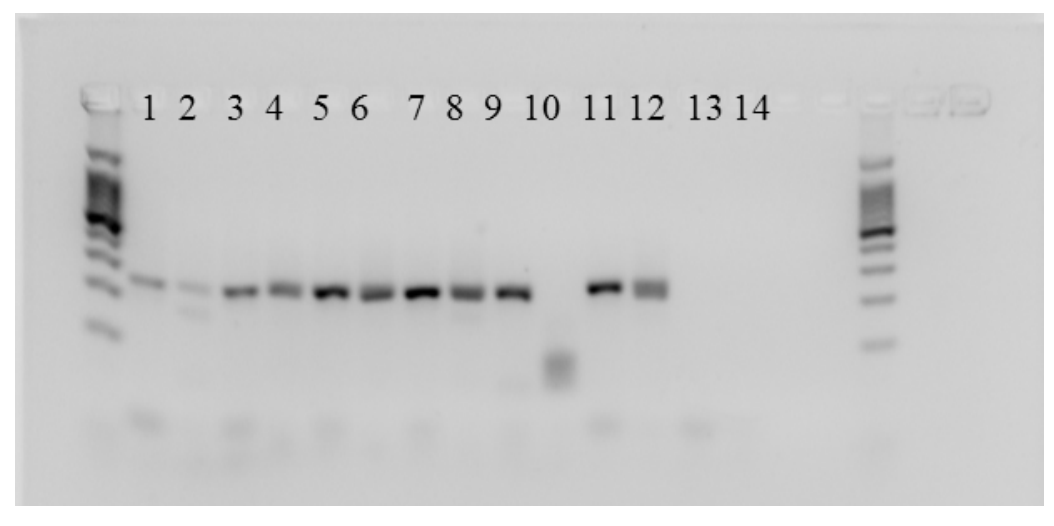

Figure S.11COBRA Region 5 in healthy samples. All samples treated with Bst-U1 for enzyme digest (ED). Lanes are as follows: 1: Male Bone Marrow PCR; 2: Male Bone Marrow ED; 3: Male Peripheral Blood 1 PCR; 4: Male Peripheral Blood 1 PCR; 5: Male Peripheral Blood 2 PCR; 6: Male Peripheral Blood 2 ED; 7: Female Peripheral Blood; 8: Female Peripheral Blood ED; 9: SssI PCR; 10: SssI ED; 11: gDNA PCR; 12: gDNA PCR; 13: Water PCR; 14: Water ED. 


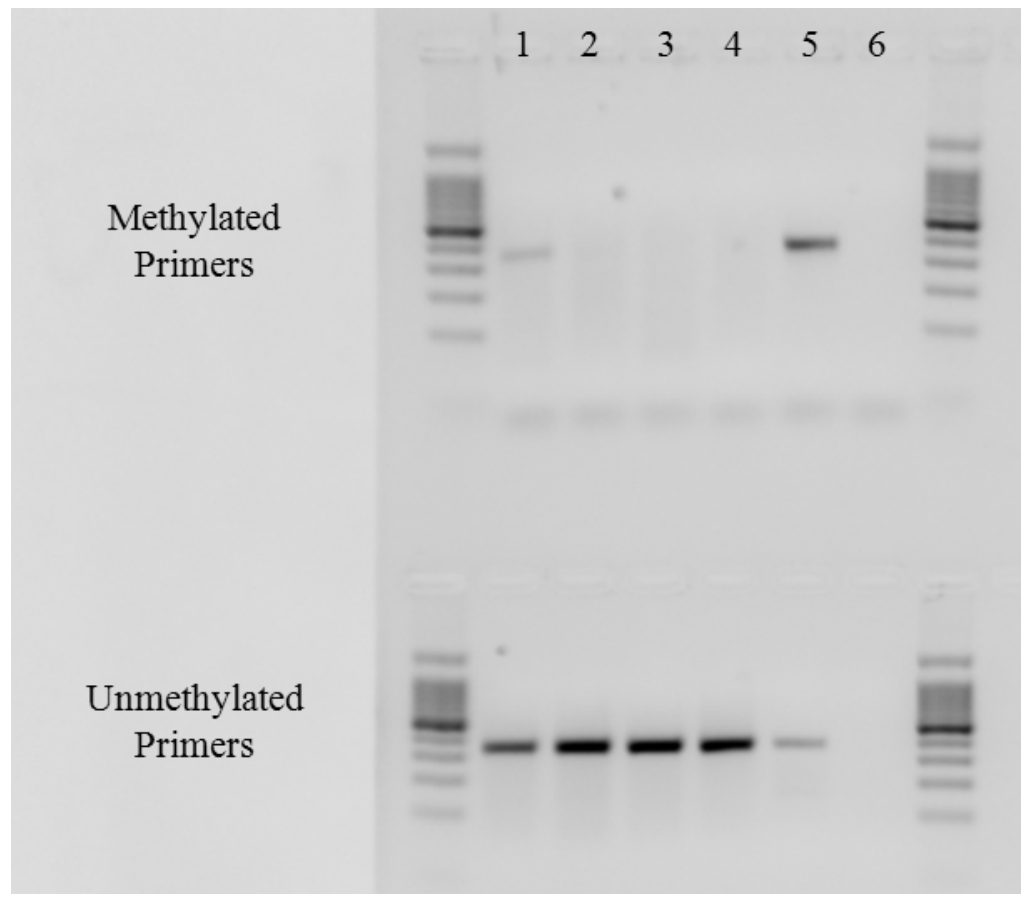

Figure S.12MSP Region 3 in myeloid malignancy cell lines.Results for the methylated primer set is on the top half of the gel and the unmethylated primer set is on the bottom half. Lanes are as follows: 1: U266B; 2: KG-1; 3: KG-1a; 4: gDNA; 5: SssI; 6: Water.

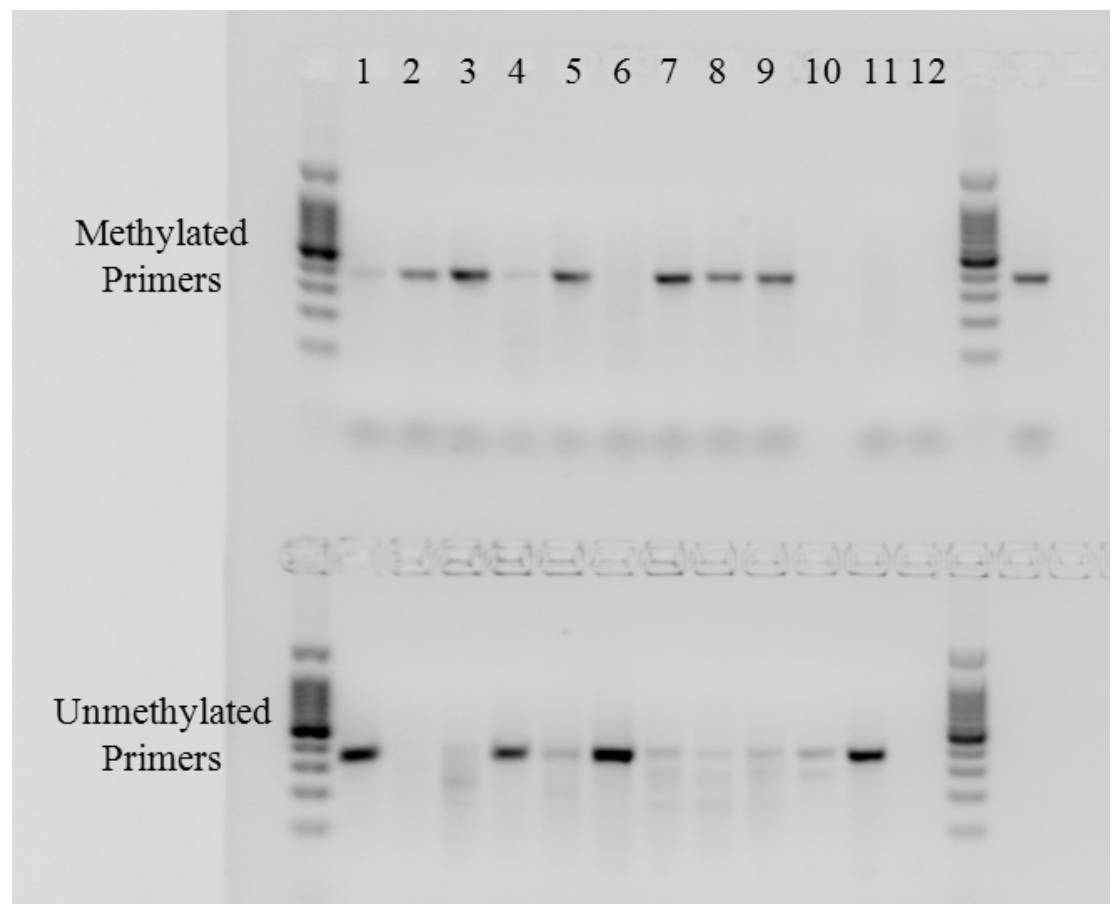

Figure S.13 MSP Region 3in lymphoid malignancy cell lines. Results for the methylated primer set is on the top half of the gel and the unmethylated primer set is on the bottom half. Lanes are as follows: 1: Call 3; 2: Nalm 6; 3: Jurkat; 4: Mec-1; 5: DB; 6: Granta; 7: RL; 8: Raji; 9: Daudi; 10: SssI; 11: gDNA; 12: Water. 


\section{$\begin{array}{llllllllll}1 & 2 & 3 & 4 & 5 & 6 & 7 & 8 & 9 & 10\end{array}$}

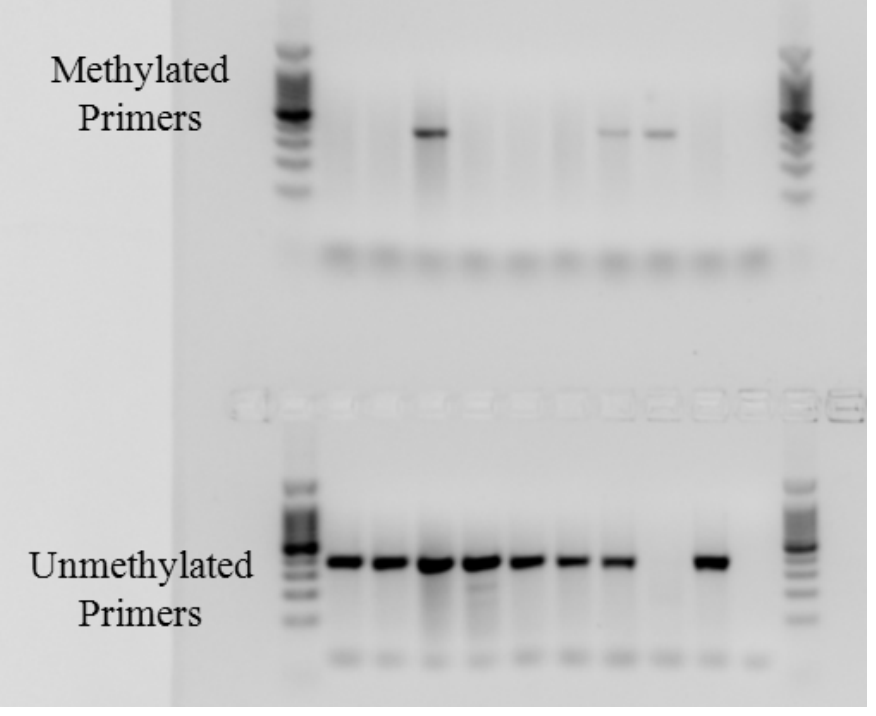

Figure S.14MSP region 3in solid tumor cell lines. Results for the methylated primer set is on the top half of the gel and the unmethylated primer set is on the bottom half. Lanes are as follows: 1: MB 231; 2: PC 36; 3: A 431; 4: Melanoma; 5: A 549; 6: WiDr; 7: Hela; 8: SssI; 9: gDNA; 10: Water.

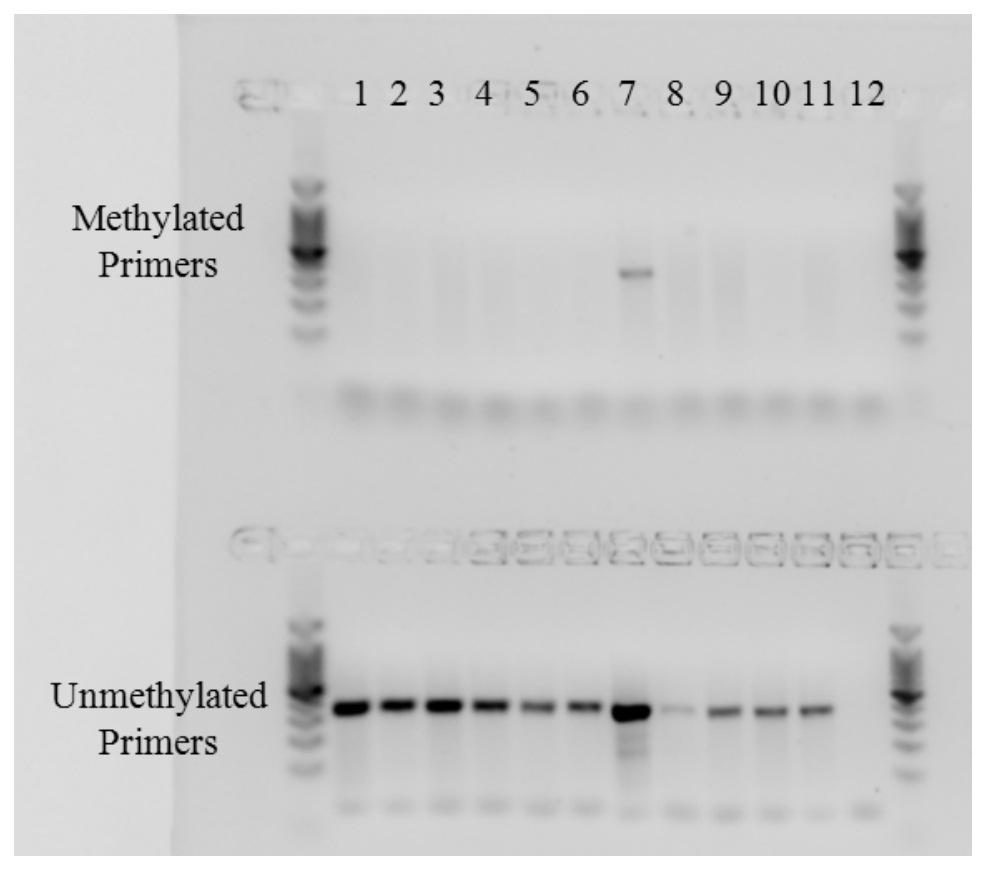

Figure S.15MSP Region 3 in healthy samples. Results for the methylated primer set is on the top half of the gel and the unmethylated primer set is on the bottom half. Lanes are as follows: 1: GM 06990; 2: GM 00536; 3: GM 05392; 4: 4674; 5: 4676; 6: KT; 7: FO; 8: HO; 9: GI; 10: SssI; 11: gDNA; 12: Water. 


\begin{tabular}{cccccc} 
& & & & & STD \\
$R U N D C 3 B$ & 1 & 2 & 3 & AVE & DEV \\
\hline Call 3 & N/A & N/A & N/A & & \\
Nalm 6 & N/A & N/A & N/A & & \\
Jurkat & N/A & N/A & N/A & & \\
Mec-1 & 29.8 & 29.7 & 29.8 & 29.7667 & 0.04714 \\
DB & N/A & N/A & N/A & & \\
Granta & 31.6 & 31.8 & 31.6 & 31.6667 & 0.09428 \\
RL & N/A & N/A & N/A & & \\
Raji & N/A & N/A & N/A & & \\
Daudi & N/A & N/A & N/A & & \\
U226B & 34.3 & 34.4 & & 34.35 & 0.05 \\
KG-1 & 28.7 & 28.9 & & 28.8 & 0.1 \\
MB 231 & 30.3 & 30.6 & & 30.45 & 0.15 \\
Hela & 27.7 & 27.4 & & 27.55 & 0.15 \\
A 431 & N/A & N/A & N/A & & \\
A 549 & 37.4 & 37 & & 37.2 & 0.2 \\
WiDr & 36.5 & 36.9 & & 36.7 & 0.2 \\
GM 06990 & 32.4 & 32.7 & 32.3 & 32.4667 & 0.16997 \\
GM 05392 & 37.1 & 37.1 & & 37.1 & 0 \\
Gm 00536 & 32.3 & 32.7 & 32.5 & 32.5 & 0.1633 \\
Cord Blood & 35 & 35.4 & 35.4 & 35.2667 & 0.18856 \\
\hline Table S.1 Real Time PCR Resuls for $R U N D C 3 B$ Expression.
\end{tabular}

Table S.1 Real Time PCR Results for RUNDC3B Expression. The above results include the $\mathrm{Ct}$ values for each run of the RUNDC3B taqman 2-step RT-PCR reactions. Analysis was performed in duplicate on select samples. These samples failed to have all three initial $\mathrm{Ct}$ values at a cut off $\mathrm{Ct}$ value (.25). The average value listed here would serve as the representative $\mathrm{Ct}$ value in any statistical analysis preformed. A "N/A" result was classified as a sample with no expression of the target gene or a $40 \mathrm{Ct}$ in data analysis. 


\begin{tabular}{|c|c|c|c|c|c|}
\hline$A B C B 1$ & 1 & 2 & 3 & AVE & $\begin{array}{l}\text { STD } \\
\text { DEV }\end{array}$ \\
\hline Call 3 & $\mathrm{~N} / \mathrm{A}$ & N/A & N/A & & \\
\hline Nalm 6 & N/A & N/A & N/A & & \\
\hline Jurkat & 33.4 & 32.9 & & 33.15 & 0.25 \\
\hline Mec-1 & 27 & 27 & & 27 & 0 \\
\hline DB & 36.7 & 36.7 & & 36.7 & 0 \\
\hline Granta & 27.7 & 28.1 & & 27.9 & 0.2 \\
\hline $\mathrm{RL}$ & 35 & 34.7 & 35.3 & 35 & 0.24495 \\
\hline Raji & 30.9 & 31.4 & 30.9 & 31.0667 & 0.2357 \\
\hline Daudi & $\mathrm{N} / \mathrm{A}$ & N/A & N/A & & \\
\hline U226B & N/A & N/A & & & \\
\hline KG-1 & 22.6 & 22.9 & & 22.75 & 0.15 \\
\hline MB 231 & N/A & N/A & & & \\
\hline Hela & 25.2 & 24.7 & 24.7 & 24.8667 & 0.2357 \\
\hline A 431 & $\mathrm{~N} / \mathrm{A}$ & N/A & N/A & & \\
\hline A 549 & 34.5 & 34.2 & 34.6 & 34.4333 & 0.16997 \\
\hline WiDr & 34.3 & 34.2 & 34.6 & 34.3667 & 0.16997 \\
\hline GM 06990 & 27.7 & 27.7 & & 27.7 & 0 \\
\hline GM 05392 & 27.9 & 27.8 & & 27.85 & 0.05 \\
\hline Gm 00536 & 27 & 26.9 & & 26.95 & 0.05 \\
\hline Cord Blood & 26.7 & 26.5 & & 26.6 & 0.1 \\
\hline
\end{tabular}

Table S.2 Real Time PCR Results for $\boldsymbol{A B C B 1}$ Expression. The above results include the $\mathrm{Ct}$ values for each run of the ABCB1 taqman 2-step RT-PCR reactions. Analysis was performed in duplicate on select samples. These samples failed to have all three initial $\mathrm{Ct}$ values at a cut off $\mathrm{Ct}$ value (.25). The average value listed here would serve as the representative $\mathrm{Ct}$ value in any statistical analysis preformed. A "N/A" result was classified as a sample with no expression of the target gene or a $40 \mathrm{Ct}$ in data analysis. 


\begin{tabular}{|c|c|c|c|c|c|}
\hline GAPDH & 1 & 2 & 3 & AVE & $\begin{array}{l}\text { STD } \\
\text { DEV }\end{array}$ \\
\hline Call 3 & 23.1 & 25.1 & & 24.1 & 1 \\
\hline Nalm 6 & 18 & 18 & 17.6 & 17.8667 & 0.18856 \\
\hline Jurkat & 18.7 & 18.4 & & 18.55 & 0.15 \\
\hline Mec-1 & 18 & 18.3 & & 18.15 & 0.15 \\
\hline DB & 18.6 & 18.3 & & 18.45 & 0.15 \\
\hline Granta & 18.8 & 18.5 & & 18.65 & 0.15 \\
\hline $\mathrm{RL}$ & 17.8 & 17.9 & 17.9 & 17.8667 & 0.04714 \\
\hline Raji & 17.7 & 17.4 & & 17.55 & 0.15 \\
\hline Daudi & 18 & 18.4 & & 18.2 & 0.2 \\
\hline U226B & 19.5 & 19.3 & 19.6 & 19.4667 & 0.12472 \\
\hline KG-1 & 18.1 & 18.6 & & 18.35 & 0.25 \\
\hline MB 231 & 17.4 & 17.5 & & 17.45 & 0.05 \\
\hline Hela & 17 & 17.2 & & 17.1 & 0.1 \\
\hline A 431 & 19.3 & 19.5 & 19.2 & 19.3333 & 0.12472 \\
\hline A 549 & 17.3 & 17 & 17.3 & 17.2 & 0.14142 \\
\hline WiDr & 18.3 & 18.2 & 18.5 & 18.3333 & 0.12472 \\
\hline GM 06990 & 18.2 & 18.1 & 18.3 & 18.2 & 0.08165 \\
\hline GM 05392 & 18.2 & 18 & 18.1 & 18.1 & 0.08165 \\
\hline Gm 00536 & 19.3 & 19.3 & & 19.3 & 0 \\
\hline Cord Blood & 19.4 & 19.7 & 19.9 & 19.6667 & 0.20548 \\
\hline
\end{tabular}

Table S.3 Real Time PCR Results for GAPDH Expression. The above results include the $\mathrm{Ct}$ values for each run of the GAPDH taqman 2-step RT-PCR reactions. Analysis was performed in duplicate on select samples. These samples failed to have all three initial $\mathrm{Ct}$ values at a cut off $\mathrm{Ct}$ value (.25). The average value listed here would serve as the representative $\mathrm{Ct}$ value in any statistical analysis preformed. A "N/A" result was classified as a sample with no expression of the target gene or a $40 \mathrm{Ct}$ in data analysis. 


\begin{tabular}{cccc} 
Region & OR & $95 \% \mathrm{CI}$ & $\mathrm{p}$ \\
\hline 1 & 1.8 & $.26-12.5$ & 0.594 \\
2 & 3.6 & $.478-27.1$ & 0.213 \\
3 & 3.6 & $.478-27.2$ & 0.213 \\
4 & 1.8 & $.26-12.5$ & 0.594 \\
5 & 1.5 & $.203-11.09$ & 0.691
\end{tabular}

Table S.4 Odds Ratios for association between RUNDC3B CGI methylation and $A B C B 1$ expression. Statistically significant associations between presence of methylation and $R U N D C 3 B$ expression established by a p-value $<0.05$.

\begin{tabular}{|c|c|} 
& Correlation with $A B C B 1 \triangle \mathrm{Ct}$ \\
Region 1 & $.433(.057)$ \\
Region 2 & $.566\left(.009^{*}\right)$ \\
Region 3 & $.417(.067)$ \\
Region 4 & $.364(.114)$ \\
Region 5 & $.574\left(.008^{*}\right)$
\end{tabular}

Table S.5 Spearman correlation results for associations between RUNDC3B CGI methylation and $\boldsymbol{A B C B} 1$ expression. Statistically significant correlations established by a p-value $<0.05$. 